IZA DP No. 4563

Sundays Are Blue: Aren't They?

The Day-of-the-Week Effect on Subjective Well-Being and Socio-Economic Status

Alpaslan Akay

Peter Martinsson

November 2009 


\title{
Sundays Are Blue: Aren't They? The Day-of-the-Week Effect on Subjective Well-Being and Socio-Economic Status
}

\author{
Alpaslan Akay \\ IZA and University of Gothenburg \\ Peter Martinsson \\ University of Gothenburg
}

Discussion Paper No. 4563

November 2009

\author{
IZA \\ P.O. Box 7240 \\ 53072 Bonn \\ Germany \\ Phone: +49-228-3894-0 \\ Fax: +49-228-3894-180 \\ E-mail: iza@iza.org
}

\begin{abstract}
Any opinions expressed here are those of the author(s) and not those of IZA. Research published in this series may include views on policy, but the institute itself takes no institutional policy positions.

The Institute for the Study of Labor (IZA) in Bonn is a local and virtual international research center and a place of communication between science, politics and business. IZA is an independent nonprofit organization supported by Deutsche Post Foundation. The center is associated with the University of Bonn and offers a stimulating research environment through its international network, workshops and conferences, data service, project support, research visits and doctoral program. IZA engages in (i) original and internationally competitive research in all fields of labor economics, (ii) development of policy concepts, and (iii) dissemination of research results and concepts to the interested public.
\end{abstract}

IZA Discussion Papers often represent preliminary work and are circulated to encourage discussion. Citation of such a paper should account for its provisional character. A revised version may be available directly from the author. 
IZA Discussion Paper No. 4563

November 2009

\section{ABSTRACT \\ Sundays Are Blue: Aren't They? \\ The Day-of-the-Week Effect on Subjective Well-Being and Socio-Economic Status}

This paper analyses whether individuals are influenced by the day of the week when reporting subjective well-being. By using a large panel data set and controlling for observed and unobserved individual characteristics, we find a large day-of the-week effect. Overall, we find a 'blue' Sunday effect with the lowest level of subjective well-being. The day-of-the-week effect differs with certain socio-economic and demographic factors such as employment, marital status and age. The paper concludes with recommendations for future analyses of subjective well-being data and design of data collections.

JEL Classification: $\quad$ C23, D60, I31

Keywords: $\quad$ subjective well-being, day-of-the-week effect

Corresponding author:

Alpaslan Akay

IZA

P.O. Box 7240

D-53072 Bonn

Germany

E-mail: akay@iza.org

\footnotetext{
* We wish to thank Andrew Oswald, Claudia Senik, Richard Easterlin, Erzo Luttmer, Alois Stutzer, Armin Falk and participants in the 6th IZA Prize Conference on Frontiers in Labor Economics: The Economics of Well-Being and Happiness, and seminar participants in Bonn University for their valuable comments. Financial support from the European Science Foundation is gratefully acknowledged.
} 
'Saturday, wait

And Sunday always comes too late

But Friday, never hesitate...'

The Cure, 'Friday I'm in Love'

\section{Introduction}

Research on subjective well-being that employs a self-reported measure as a proxy for utility has increased rapidly in economics since the 1990s (see overviews in e.g. Dolan et al., 2008; Frey and Stutzer, 2002; van Praag and Ferrer-I-Carbonell, 2004). ${ }^{3}$ As a result of this research, we obtain insights that are difficult to gain when using a standard neo-classic economic approach, for example the large disutility from being unemployed (Winkelmann and Winkelmann, 1998; Clark and Oswald, 1994; Clark, 2003), that age and subjective well-being have a U-shaped relationship with a minimum around the age of 40 (Frey and Stutzer, 2002), that married people have higher subjective well-being than singles (Clark and Oswald, 1994), and that both absolute and relative income affect subjective well-being (Easterlin, 1995; Clark et al., 2008).

Besides individual characteristics and macroeconomic factors, subjective well-being can be explained by many other important temporary life circumstances, and these are often linked to specific days of the week. Most people experience a rhythmic weekday-weekend separation based on their employment status, which has implications for number of hours of sleep, wake-up time and bedtime hours (Yang et al., 2001), different consumption patterns on different days of a week (Cherpitel et al., 1998) and social life and stress levels

\footnotetext{
${ }^{3}$ For overviews by psychologists, see e.g. Diener et al. (1995), Diener et al. (1998) and Kahneman et al. (1999).
} 
(see Areni and Burger, 2008, for many other related findings and a review). In the psychological literature, it has long been discussed whether the days of the week have different influences on the subjective well-being (as well as on many other mood characteristics) of individuals (e.g. Farber, 1953; Snyder et al., 1977; Clark and Watson, 1988; Csikszentmihalyi and Hunter, 2003; Egloff et al., 1995; Kennedy-Moore et al., 1992; Neale et al., 1987; Rossi and Rossi, 1977). ${ }^{4}$

The objective of the present paper is to examine whether subjective well-being, which is used as a proxy for an individual's utility, is influenced by the day of the week. This is done using the German Socio-Economic Panel (GSOEP), which is one of the longest panel data sets available. It includes a measure of subjective well-being that spans more than twenty years and is framed as: 'How satisfied are you at present with your life, all things considered?' 0 (completely dissatisfied) and 10 (completely satisfied). The measure intends to capture overall well-being of an individual and is expected not to fluctuate in short time intervals such as from one day to the next in the same week. Yet, the linguistic structure of the question really pins down the degree to which respondents judge the quality of their life at present considering all things (Veenhoven, 1991); i.e. the response is probably affected by the momentary circumstances of the respondent when the question is asked. ${ }^{5}$ Already Kahneman et al. (1999) argued that people assess their well-being at any

\footnotetext{
${ }^{4}$ Biologists and psychologists identified the so-called Circaseptum rhythms in some physiological processes. It indicates that some physiological processes show seven day cycles. For instance, immune system responses to disease, body temperature and red-blood-cell count all exhibit a 7-day cyclic pattern (for a review, see Larsen and Kasimatis, 1990; Larsen and Kasimatis, 1991; Croft and Walker, 2001).

${ }^{5}$ It should be noted that the English translation of the question differs slightly between different waves, while the question is asked exactly the same in German in all waves as "Wie zufrieden sind Sie gegenwärtig, alles in allem, mit Ihrem Leben?” The English translation of this question is reported in text. For the details of the survey instruments see www.diw.de.
} 
given moment by examining the events and the circumstances in the short proximity of the time that the overall subjective well-being question is prompted.

Croft and Walker (2001) suggest that there is a commonly held belief that Mondays are blue. Supportive of this view is that well-being generally is higher on weekends since weekends may have more pleasant daily events than other days of a week and thus subjective well-being might also be varied between the traditional working week and the weekend (Stone, 1987). Another view is that well-being is very low at the end of the week. This has been coined Sunday neurosis (e.g. Mihalcea and Liu, 2006; Areni and Burger, 2008), and may be due to people planning ahead for the upcoming work week more on Sundays than on other days (Clark and Watson, 1988). Another explanation for the same effect is given by Csikszentmihalyi (1997), who argues that people feel the best when occupied by tasks with clear structure, e.g. clear objectives and rules, which are mostly lacking during leisure time.

The results from studies using the experience sampling method, which is a method where people are asked to report where they are and what they are doing at several times during the day on several days of the week, ${ }^{6}$ suggest that overall subjective well-being fluctuates across the days of a week (Csikszentmihalyi and Larsen, 1987; Csikszentmihalyi and Hunter, 2003; Larsen and Kasimatis, 1990). Some studies report a blue-Monday effect, implying that individuals systematically report lower subjective well-being on Mondays

\footnotetext{
${ }^{6}$ Kahneman et al. (1999) interpret this method as measuring point-instant utility of immediate environmental circumstances as being based on recording within-individual affective experiences for the randomly assigned short time intervals during a day to capture the dynamics of well-being in daily life and with a limited number of observations.
} 
(Stone et al., 1985; Egloff et al., 1995; Larsen and Kasimatis, 1990; McFarlane et al., 1988; Reis et al., 2000). ${ }^{7}$ Mihalcea and Liu (2006) find that well-being is influenced by the day of the week: the happiest day is Saturday and the bluest day is Wednesday (i.e. hump day) and partly Sunday, possibly because people may come to realise that another long week is about to start. Focusing on job satisfaction and mental health, Taylor (2006) analysed the day-of-the-week effect using the British Household Panel Survey (BHPS). He finds that individuals interviewed on a Friday report higher levels of job satisfaction and also higher levels of mental health compared to the individuals interviewed mid-week. He concludes that people assign a higher (lower) premium on leisure time over work and this may result in lower (higher) level of reported job satisfaction on weekdays (weekends).

Our results suggest that overall subjective well-being is largely influenced by the day of the week it is reported. We find that Sunday is the bluest day in Germany; i.e. this is the day that individuals on average report the lowest level of subjective well-being. Saturday and Friday are the other two days that individuals report lower subjective well-being. Hence, weekends result in lower subjective well-being than weekdays. The main advantage of the present paper is that the data set is very large and can allow us to identify the subgroups that drive these results. A separate analysis based on different socioeconomic and demographic characteristics of individuals reveals that there are different weekly patterns of subjective well-being, where the most pronounced effect is found among married and middle-aged people. Moreover, we analysed the potential problem of endogeneity since both interviewers and interviewees may self-select themselves to certain

\footnotetext{
${ }^{7}$ It is also shown that the frequency of suicide attempts and short-term absence from work is higher and labour productivity is lower on Mondays (Maldonado and Kraus, 1991; Nicholson et al., 1978).
} 
interview days, but found that the results are quite robust to interviewer and self-selection effects.

The remainder of the paper is organised as follows: We describe the data set in Section 2, and in Section 3 we present the econometric methods used in the empirical analysis with a focus on the panel aspect of the data to control for unobservable influences on subjective well-being, which are potentially correlated with observed individual characteristics. Section 4 contains the results. First we show descriptive analyses of subjective well-being for each day of the week for the whole sample and then for sub-samples followed by the results from the econometric analyses, again for the whole sample and then for subsamples. In Section 5 we investigate self-selection by interviewers and interviewees. Finally, Section 6 concludes the paper.

\section{The data}

\subsection{The sample}

In this paper, we use the GSOEP data set, which has been widely used to investigate various issues related to subjective well-being (e.g. Winkelmann and Winkelmann, 1998; van Praag et al., 2003; Frijters et al., 2004). This panel data set originally consisted of more than 12,000 individuals and 6,000 households in 1984, and contains detailed information about the individuals and the households. The individuals are interviewed each year and the data set is maintained by following all individuals aged 16 and older in the 
household. Since the dates of the interviews, which are needed for our purposes, are not available for the 1984 wave, we use data from 1985 to 2007.

The GSOEP data set contains detailed information on the interviews: (i) the date of the interview (day, month and year), which enables us to calculate the day of the week the interview was conducted, and (ii) a unique identification number for each interviewer. Table 1 shows the descriptive statistics of the interviews listed by the day of the week for the sample used in the analysis. First we present the total number of interviews conducted and then the proportion of interviews conducted on each day of the week. As shown, most of the interviews were conducted on Mondays, Tuesdays and Wednesdays, while fewer interviews were conducted on Thursdays, Fridays, Saturdays, and in particular on Sundays. Table 1 also presents more detailed descriptive statistics related to the proportion of individuals who were (i) never interviewed on a particular day of the week, (ii) interviewed at least once on a particular day of the week but not always and (iii) always interviewed on a particular day of the week. Almost 32\% of the individuals were never interviewed on a Monday, while the same statistic for a Sunday is $67 \%$. The proportion of individuals who were never interviewed on a particular day of the week increases at the end of the week. It should however be noted that only a very small fraction of individuals were always interviewed on the same day of the week.

Table 1 about here 
Table 2 provides a more detailed analysis of the interviews. We report average number of interviews for each day of the week for those who were interviewed seven times or less and those who were interviewed more than seven times in the GSOEP data set separately. This allows us to compare the pattern between those who were interviewed more than seven times, i.e. which in principle could mean that the individual were interviewed at least once every day of the week, and the others. Table 2 shows that the proportion of individuals who were never interviewed on a Monday is 50\% among those who were interviewed seven times or less, while the same proportion is only $14 \%$ for those interviewed more than seven times. Similarly, the proportion of the individuals who were interviewed on a particular day is very small among those interviewed seven times or smaller and even less for those interviewed more than seven times.

\section{Table 2 about here}

There seems to be evidence that the day of the week on which an interview takes place is not truly random. This raises the question whether there is systematic self-selection among interviewees and/or interviewers resulting in interviews taking place on particular days of the week. Thus, the chosen interview day may not be truly exogenous, i.e. may not be randomly assigned. Furthermore, it is not truly endogenous to the interviewee since a significant portion of the interview dates were decided jointly between interviewers, and almost half of the individuals in the sample (48\%) were interviewed on seven different days of the week and this fraction constitutes $26 \%$ of the whole sample of individual-year observations. The most natural constraint of day to be interviewed is one's work schedule. 
For instance, we can speculate that individuals who work weekdays may have no other option than to be interviewed on the weekend. Table 3 shows descriptive statistics on different interview days for different employment states. In contrast to expectations, the distribution does not differ much between those employed and those unemployed or parttime employed. ${ }^{8}$ This may be another indication that the day of the interview is not totally the result of self-selection with respect to individual characteristics of the respondent. Another factor that may influence the self-selection process is the mode of the interview. There are different interview modes used in the collection of GSOEP data set: oral interview, written interview with interviewer, written interview without interviewer and computer assisted interviews. We discuss this issue in more detail in Section 6 when we discuss endogeneity. ${ }^{9}$

\section{Table 3 about here}

\section{Econometric framework}

The subjective well-being in GSOEP is reported on an 11-point scale ranging from 0 (completely dissatisfied) to 10 (completely satisfied). Since the measure of subjective wellbeing is an ordinal discrete variable, the econometric method used in the present study is based on an ordered probit approach, which is the commonly used approach in this type of studies (e.g. Clark and Oswald, 1994; Frey and Stutzer, 2002; van Praag and Ferrer-I-

\footnotetext{
${ }^{8}$ We did the same exercise for some other subgroups such as married, single, divorced, widowed, age categories and regions. The patterns for these subgroups are not much different from the subgroups of employed and unemployed. The results can be provided upon request.

${ }^{9}$ See http://www.diw.de/documents/dokumentenarchiv/17/43529/soep_overview.pdf for detailed information on the data collection process.
} 
Carbonell, 2004). ${ }^{10}$ In this modelling approach, the actual subjective well-being is assumed as latent, where researchers can only observe the self-reported subjective well-being on a discrete scale. In order to test the null hypothesis of no day-of-the-week effect on subjective well-being, we need to control for observed and unobserved individual characteristics resulting in the ordered probit model

$$
S W B_{i t}^{*}=x_{i t}^{\prime} \beta+D_{i t}^{\prime} \gamma+\varepsilon_{i t},
$$

where $i=1, \ldots, I$ indicates individuals and $I$ is the total number of individuals; $t=1, \ldots, T_{i}, \forall i \in I$ is time and $T_{i}$ is the number of time periods an individual $i$ was interviewed (unbalanced panel data); $X_{i t}$ is a vector of socio-demographic and economic characteristics such as age, marital status and income for individuals $i$ at time $t$, and $\beta$ is the corresponding parameter vector to be estimated; $D$ contains seven indicator variables for the day of the week and $\gamma$ is the corresponding vector of parameters to be estimated. As suggested in psychology literature (e.g. Diener et al., 1999), subjective well-being of individuals may be explained by unobserved personality traits (such as extraversion or neuroticism). In order to control for unobserved personality traits, the error term is specified as $\varepsilon_{i t}=\alpha_{i}+u_{i t}$, where $\alpha_{i}$ denotes time-invariant unobserved personality traits, which are assumed to be normally distributed with zero mean and constant variance $\sigma_{\alpha}^{2}$; and $u_{i t}$ is the usual error term, which is assumed to be normally distributed with zero mean and unit variance due to identification.

\footnotetext{
${ }^{10}$ Ferrer-I-Carbonell and Frijters (2004) find no large difference when comparing the results from using OLS (assuming cardinality) and an ordered probit approach (assuming ordinality).
} 
We assume that the unobserved individual effects $\alpha_{i}$ are orthogonal to both observed individual characteristics and the error terms by specifying a random-effects model. However, the unobserved individual characteristics might be correlated with observed individual characteristics $\left(E\left[x_{i t} \mid \alpha_{i}\right] \neq 0\right)$. A fixed-effects model could have been used to take this correlation into account had we preferred to use an OLS regression with fixedeffects. However, due to the nonlinear nature of the ordered probit model, the fixed-effect model with individual dummies might be highly biased, i.e. the incidental parameters problem (Newman and Scott, 1948). Instead, it is possible to apply a quasi-fixed-effects model (the correlated random-effects model of Chamberlain, 1984) using an auxiliary distribution for the unobserved individual characteristics specified as $\alpha_{i}=\bar{x}_{i}^{\prime} \phi+v_{i}$, where $\bar{X}$ is the within-means of time-varying observed characteristics of the individuals such as age and income; $\phi$ is the vector of parameters to be estimated; and the new unobserved individual effects $v_{i}$ are assumed to be normally distributed with zero mean and variance $\sigma_{v}^{2}$ and orthogonal to observed characteristics and the usual error terms.

We also control the model for unobserved temporal and spatial variations, which may influence subjective well-being. Subjective well-being can be affected by transitory macroeconomic conditions over time, such as economic financial crises and inflation, or different cohorts in the data set may perceive the subjective well-being question differently. There could also be a trend effect on subjective well-being. Consequently, we include time-specific fixed effects to control for unobserved variations over time both for 
year effects and month effects (note that no interviews were conducted in November and December). Germany is a large country and regional unobserved heterogeneity affecting the subjective well-being is quite possible. Thus, we also included state-level regional fixed-effects to capture spatial differences among the 16 German states.

The model discussed above is estimated using a maximum likelihood estimator. $S W B_{i t}^{*}$ is latent, and we observe the subjects' self-reported $S W B_{i t}$ from 0 to 10 . This can be summarised as

$$
\begin{gathered}
S W B_{i t}=j \text { if } \mu_{j-1}<S W B_{i t}^{*} \leq \mu_{j}, j=0, \ldots, J=10, \\
\mu_{0}=-\infty, \mu_{j} \leq \mu_{j+1}, \mu_{J}=\infty,
\end{gathered}
$$

where $\mu_{j}$ is the unknown upper cut-off point for category $j$ of the ordered relationship to be estimated. If we assume that the probability of falling into self-reported category $j$ for an individual $i$ at time $t$ is $P\left(S W B_{i j}=j\right)$, we can write the probability as

$$
P\left(S W B_{i t, j}=j\right)=\Phi\left(\mu_{j}-x_{i t}^{\prime} \beta-D_{i t}^{\prime} \gamma-\bar{x}_{i}^{\prime} \phi-v_{i}\right)-\Phi\left(\mu_{j-1}-x_{i t}^{\prime} \beta-D_{i t}^{\prime} \gamma-\bar{x}_{i}^{\prime} \phi-v_{i}\right),
$$

where $\Phi$ is the distribution function of the standard normal random variable. The parameters of the model can then be estimated with the maximum likelihood estimator using the Gaussian-Hermite Quadrature to integrate out the unobserved individual heterogeneity (Butler and Moffitt, 1982). 


\section{Results}

\subsection{Descriptive results}

We start by presenting some figures and descriptive statistics of subjective well-being on different days. Figure 1, which shows the average values for the whole sample, indicates that subjective well-being is fairly stable during the weekdays except for a small decrease on Wednesdays and Fridays. However, there is a sharp 3-day continuous drop starting on Fridays. The average level of subjective well-being over the first four days of the week is 7.04 while during the remaining three days it is 6.94 . The difference is significant at the 1\% level based on a chi-square test. Similarly, the difference in subjective well-being between Mondays and Sundays is 0.185 and the null hypothesis of equality can be rejected at the $1 \%$ level using a chi-square test.

\section{Figure 1 about here}

To gain a more detailed understanding of how subjective well-being is affected by the day of the week, we separate the sample into several subgroups identified by socio-economic characteristics. Figure 2 presents subjective well-being for employment-status; full-time employed, part-time employed and unemployed. As found in previous research, unemployment causes a significant reduction in subjective well-being, where the average subjective well-being for full-time employed individuals is 7.12 compared to only 6.80 for the unemployed. Subjective well-being is relatively flat for full-time empoyed individuals 
across the weekdays with a sharp reduction on Sundays. Part-time employed people experience a drop on Mondays and Wednesdays following a sharp and almost linear reduction from Thursday to Sunday. The pattern of subjective well-being over the days of the week is slightly different for the unemployed: Their subjective well-being shows a small increase during weekdays until Thursday, but then falls dramatically. However, overall these three figures look similar in that they all indicate a systematic reduction in subjective well-being during weekends. Interestingly, the results seem to suggest that the weekend blues is not related to employment status. In Section 4.3, we analyse this issue in more detail by using a regression approach to control for socio-economic factors that may explain differences between different employment states.

Figure 2 about here

We explore other socio-demographic characteristics that may show different patterns of subjective well-being over the week as well: (i) marital status (Figure 3); region (former East and West Germany) (Figure 4); (iii) natives and immigrants (Figure 5); (iv) gender (Figure 6); and (v) age (Figure 7). The day-of-the-week effect on subjective well-being differs depending on marital status. The subjective well-being for the married is stable over the weekdays with a small reduction on Fridays and a sharp decrease during the weekend. The subjective well-being among single people is quite stable over the week, and there is only a small decline towards the end of the week. In absolute terms, married people show a sharper decline in subjective well-being on Sundays than do singles. Those who are divorced and those who are widowed show a lower absolute level of subjective well-being, 
but the level is more stable over all days of the week compared to for those who are married.

Figure 3 about here

Figure 4 shows that the former East and West Germany are very different in terms of the day-of-the-week effect on subjective well-being. People in the former West Germany show a fairly stable weekday effect on subjective well-being and a sharp decline on weekends, while people in former East Germany report an almost constant level of subjective wellbeing throughout the week including Sundays. However, the latter group's absolute level of subjective well-being is remarkably lower than that of the former West Germans.

Figure 4 about here

Figure 5 shows that natives and immigrants are similar in absolute terms on weekdays in terms of subjective well-being, but that immigrants are much less affected by weekends in terms of decreased subjective well-being. This might be related to lifestyle differences between the two groups. Figure 6 shows the gender effect on subjective well-being over the weeks. The general trend is the same except that males experience a sharper drop on Sundays than do females. Figure 7 shows that there is a U-shaped relationship between age and subjective well-being. Every age group from 26 to 65 reports declining subjective well-being on weekends. There is no effect among those 25 and younger, and it tends to decrease again in the older ages as we observe a lower weekend effect for those above age 65. 
Figure 5 about here

Figure 6 about here

Figure 7 about here

\subsection{Regression results}

The descriptive statistics suggest that subjective well-being is affected by the day of the week, but that there are differences between subgroups of individuals. However, the descriptive analyses of subjective well-being are not conditioned on observed and unobserved individual characteristics. Thus, we apply econometric analysis by regressing subjective well-being on individual characteristics as well as on the days of the week, month, year and regional fixed-effects. The results of this regression are reported in Table 4. We present the results from three models: (i) the pooled ordered probit model, which does not control unobserved individual effects; (ii) the random-effects ordered probit model, which controls for unobserved individual characteristics; and (iii) the quasi-fixedeffects model, which controls for unobserved individual characteristics that are correlated with observed individual characteristics.

The overall results are in line with previous findings, e.g. the healthier, richer, married and employed have higher subjective well-being (see e.g. Frey and Stutzer, 2002; Dolan et al., 2008). The difference between the first two models is that the second accounts for unobserved individual characteristics such as personality traits on subjective well-being, 
and we can reject the hypothesis of homogeneity at the $1 \%$ significance level. The quasifixed-effect model shows almost the same results as those obtained by using a randomeffects approach, with the difference that the magnitudes of the parameters are smaller with the quasi-fixed-effects model, especially for Fridays, Saturdays and Sundays. They are also less significant. Overall, the regression results support the descriptive findings in Figure 1, showing a sharp decline in subjective well-being during the weekend. In all three regressions, we control for time fixed-effects both for years and months (in addition to day of the week). The estimation results, which for space reasons are not reported in the tables, suggest that there is a decline in subjective well-being over time. This effect is less apparent when we control for unobserved individual heterogeneity using a random-effect or quasi-fixed-effects specifications. There was no interview in November and December, and we only use nine month dummies (January is the base category) in the analyses. Compared to January, individuals reported significantly higher levels of subjective wellbeing in May and June.

Table 3 about here

\subsection{Day-of-the-week and socio-economic characteristics}

To better understand how the days of the week affect different sub-groups, we run separate regressions models for sub-groups within employment status, marital status, place of residence, nationality and age. Table $5 a$ and $5 b$ show the quasi-fixed-effects estimates of these models. For brevity, we only report the day-of-the-week effect. ${ }^{11}$ As already could be

\footnotetext{
${ }^{11}$ Full results are available upon request.
} 
read in figures in the previous section, the effect of the day of the week, especially for weekends, differs substantially between different sub-groups. We find similar results with econometric analysis when we condition on observed and unobserved individual characteristics. Estimating different models for employment status reveals that there is a relationship between employment status and the day-of-the-week effect. The full-time employed experienced a significantly lower subjective well-being on Fridays, Saturdays and Sundays compared to on Mondays, while for part-time employed only Saturdays and Sundays are significant and for unemployed only Sundays. It is also observed that the slope of the decrease in subjective well-being on weekends is the steepest for the full-time employed (Table 5a). However, only the Sunday dummy is statistically significant for the unemployed. Married individuals reported a significantly lower level of subjective wellbeing on Fridays, Saturdays and Sundays, while single, widowed and divorced individuals do not show a significant day-of-the-week effect (except Mondays for single people). The results for people living in areas of the former West and East Germany are substantially different (Table 5b). Compared to on Mondays, West Germany residents reported a significantly higher subjective well-being on other weekdays and significantly lower wellbeing on Sundays. The regression does not show the same pattern for East Germany residents, who only report a significantly lower subjective well-being on Fridays than on Mondays. Females and males experience almost the same day-of-the-week effect and report lower subjective well-being during Saturdays and Sundays (Table 5b). Finally, among those 25 years old or younger, there is no day-of-the-week effect, while there is a significant Sunday effect in the 26-35 group. In the 36 to 55 age range, there are significant 
Saturday and Sunday effects, whereas there is no day-of-the-week effect for those older than 55 (Table 5c).

Table 4a about here

Table $4 b$ about here

Table 4c about here

\section{Interviewer effect and self-selection to day of interview}

One important issue that can substantially affect the results presented above is that the choice of interview day may not be random. It might be the case that individuals with higher or lower subjective well-being are self-selected to be interviewed on some specific days of the week. For instance, based on the results presented above, the individuals who already have lower subjective well-being may systematically choose to be interviewed during weekends. Failing to take this self-selection problem into account may bias the results. In our case, both the interviewer and the respondent may self-select themselves to be interviewed on a certain day. First we test for interviewer selection of the day of the interview and second for the subject (respondent) selection of the day of the interview.

The actual decision regarding on which day the interview will take place is based on a phone call from the interviewer, who suggests a date for the interview. In case the respondent cannot be interviewed on this specific date, they jointly try to find another day for the interview. Thus, unobserved interviewer characteristics may affect which day is 
scheduled, especially the initial day suggested by the interviewer. To control for this effect, we specify an interviewer fixed-effects model for both the whole sample and for different sub-groups. The results are reported in Table 6 . We only show the parameters for the dayof-the-week effect for space reasons, and the results for the other variables are pretty very much in line with what we reported above. Using an F-test, we cannot reject the hypothesis of an interviewer fixed-effect at the 5\% significance level. This indicates that the day-ofthe-week effect does not seem to be caused by the unobserved characteristics of the interviewers.

\section{Table 6 about here}

We test for self-selection among interviewees. To test this hypothesis, we use a two-step modelling approach where we instrument the probability of being interviewed in a particular day. In the first step, we estimate the probability of being interviewed on a day using a quasi-fixed-effects probit model. In the second step, we use the predicted probability of the first model in the subjective well-being regression using a quasi-fixedeffects approach to test for self-selection. We apply a two-step approach for Saturdays and Sundays, which are the days with the fewest interviews. Additionally, we combine these two days and test the endogeneity of weekends (Saturdays and Sundays together)

The two-step estimation approach requires instruments, i.e. identification (or exclusion) restrictions, to be able to identify the day-of-the-week effect in the subjective well-being equation. Thus, we need to find robust instruments that affect the probability of being interviewed on a particular day without affecting the respondent's subjective well-being. 
However, this is not an easy task. We use three instruments: (i) change of interviewer, (ii) the mode of the interview and (iii) mean number of interviews on a specific day. The change of interviewer from one wave of the panel to the next can be seen as an external exogenous shock and should not be correlated with subjective well-being. With respect to mode of the interviews, a non-negligible proportion of interviews are not oral interviews but rather conducted using other modes such as computer assisted telephone interviews and written interview with and without an interviewer. The mode of interview may affect the chosen interview day, but it is not expected to be correlated with subjective well-being. The third set of instruments is based on the mean number of interviews on each day of the week. These variables can be interpreted as an indicator for the underlying self-selection process by individuals to a particular day of the week. In summary, change of interviewer, mode of the interview and mean number of interviews are assumed not to be correlated with subjective well-being, but may affect the chosen day of the week when the interview takes place.

The two-stage regression results (not reported here but available upon request) suggest that the parameters for change of interviewers have a significant and negative impact on the probability of being interviewed on a Saturday, a Sunday or on a weekend. Compared to oral interviews, written interviews with and without an interviewer decreased the probability of being interviewed on Saturday, Sunday or on a weekend, while computer assisted telephone interviews had the opposite effect. Table 7 shows the results of the twostage regressions. The results show that our main findings regarding the day-of-the-week effect are not driven by subject self-selection. Saturdays, Sundays and weekends have a 
significant and negative effect on subjective well-being, which is in line with the main results presented above. ${ }^{12}$

\section{Table 7 about here}

\section{Discussion and conclusion}

Over the last decade there has been an increased interest in subjective well-being analysis in economics. By using GSOEP, which is one of the longest panel data sets measuring subjective well-being, we investigated whether there is a day-of-the-week effect on reported subjective well-being. We find a strong day of the week effect on subjective wellbeing even after controlling for the observed and unobserved characteristics of the individuals which are assumed to be correlated. In more detailed analyses, we investigated the effects of the day of the week on subjective well-being among people in different subgroups. The results suggest that the day-of-the-week effect is primarily explained by employed and married natives living in the former West Germany. We also tested for potential self-selection to the day of the interview among interviewers and interviewees, but could not reject the hypothesis of self selection in either case.

Both descriptive statistics and results from econometric analyses show lower and declining subjective well-being on weekends compared to on weekdays. Sundays are found to be the bluest day, although this result differs somewhat among different socio-demographic

${ }^{12}$ We also experimented with different combinations of exclusion restrictions. The results were very sensitive to the instrument used in the analysis. However, the results were in line with our main findings for most of the cases, i.e. negative and significant weekend effects, although the difference in magnitude of the estimated parameters is sometimes very large. 
groups. Thus, our results are in line with previous results that some day or days of the week are blue (Csikszentmihalyi and Larsen, 1987; Csikszentmihalyi and Hunter, 2003; Larsen and Kasimatis, 1990). However, in contrast to e.g. Taylor (2006), who pointed to a positive effect of Fridays on subjective well-being (measured as job satisfaction and mental health), we find a 'blue weekend' effect, supporting the so-called Sunday neurosis. The results are transparent in the sense that people cannot isolate themselves from the actual present events in life when asked to report their subjective well-being.

Our findings provide initial evidence of the day of the week effect on subjective well-being in economics research. The paper suggests three important conclusions regarding survey design and analysis of subjective well-being data. First, the fact that subjective well-being is affected by the day of the interview suggests that controls for the day-of-the-week effect should always be included. In our case, however, we do not find that the estimates of the socio-economic variables are affected, but this is not surprising given the large panel data set used. Second, both interviewers and interviewees may self-select themselves to certain days of the week. In the case of new data collection on subjective well-being, there should be an a priori strategy to handle the potential day-of-the-week effect, especially when working with small sample sizes. This is ideally done by using randomisation. If secondary data is used, the potential problem of self-selection should be considered. Finally, the exact formulation of the subjective well-being question may influence how much individuals focus on the moment in time when the question is asked (see discussion in Kahneman et al, 1999). Clearly, further work is needed to better understand which particular factors generate the day-of-the-week pattern observed in the present paper. 


\section{References}

Areni, C.S., and Burger, M. (2008). Memories of "Bad" Days Are More Biased Than Memories of “Good” Days: Past Saturdays Vary, but Past Mondays Are Always Blue. Journal of Applied Social Psychology 38: 1395-1415

Bertrand, M. and Mullainathan, S. (2001). Do People Mean What They Say? Implications for Subjective Survey Data. The American Economic Review. Papers and Proceedings of the Hundred Thirteenth Annual Meeting of the American Economic Association 91: 67-72

Butler, J. S. and Moffitt, R. (1982). A Computationally Efficient Quadrature Procedure for the One-Factor Multinomial Probit Model. Econometrica 50: 761-764

Chamberlain, G. (1984). Panel Data, in Handbook of Econometrics, Vol. II, edited by Zvi Griliches and Michael Intriligator. Amsterdam: North Holland.

Cherpitel, C., Meyers, A., and Perrine, M. (1998). Alcohol consumption, sensation seeking, and ski injury: A case control study. Journal of Studies on Alcohol 59: 216-221

Clark, A.E., and Oswald, A.J. (1994). Unhappiness and Unemployment. Economic Journal 104: 648-659

Clark, L.A., and Watson D. (1988). Mood and the mundane: Relations between daily life events and self-reported mood. Journal of Personality and Social Psychology 54: 296-308

Clark, A., (2003). Unemployment as a Social Norm: Psychological Evidence from Panel Data. Journal of Labour Economics 21: 323-351

Clark, A.E., Frijters, P., and Shields M.A. (2008). Relative Income, Happiness, and Utility: An Explanation for the Easterlin Paradox and Other Puzzles. Journal of Economic Literature 46: 95-144

Croft, G., and Walker, A. (2001). Are Monday blues all in the mind? The role of expectancy in the subjective experience of mood. Journal of Applied Social Psychology 31: 1133-1145

Csikszentmihalyi, M. (1990) Flow: The psychology of optimal experiences, New York, Harper and Row.

Csikszentmihalyi, M., and Larson, R.W. (1987). The Experience Sampling Method. Journal of Nervous and Mental Disease 175: 526-536 
Csikszentmihalyi, M., and Hunter, J. (2003). Happiness in everyday life: The uses of experience sampling. Journal of Happiness Studies 4: 185-199

Diener, E. (1984). Subjective well-being. PsychoL Bull 95: 542-575

Diener, E., Diener, C., and Diener, M. (1995). Factors predicting the subjective well-being of nations. Journal of Personality and Social Psychology 69: 851-864

Diener, E., Sapyta, J.J., and Suh, E.M. (1998). Subjective Well-Being Is Essential to WellBeing. Psychological Inquiry 9:133-37

Diener, E., Suh, E.M., Lucas, R.E., and Smith, H.L. (1999). Subjective Well-Being: Three Decades of Progress. Psychological Bulletin 125: 276-303

Dolan, P., Peasgood, T., and White, M. (2008). Do we really know what makes us happy? A review of the economic literature on the factors associated with subjective wellbeing. Journal of Economic Psychology 29:92-122

Easterlin, R. (1995). Will Raising the Incomes of All Increase the Happiness of All? Journal of Economic Behavior and Organization 27: 35-47

Egloff, B., Tausch, A., Kohlmann, C., and Krohne, H. (1995). Relationships between time of day, day of the week, and positive mood: Exploring the role of the mood measure. Motivation and Emotion 19: 99-110

Ekman, P., Davidson, R., and Friesen, W. (1990). The Duchenne Smile: Emotional Expression and Brain Physiology II. Journal of Personality and Social Psychology 58: 342-353

Farber, M. L. (1953). Time-perspective and feeling-tone: A study in the perception of days. Journal of Psychology 35:253-257

Falthzik, A. (1972). When to make telephone interviews. Journal of Marketing Research 19:451-452

Ferrer-i-Carbonell, A., and Frijters, P. (2004). The effect of methodology on the determinants of happiness. The Economic Journal 114: 641- 659

Frey, B.S., and Stutzer, A. (2002). What Can Economists Learn from Happiness Research? Journal of Economic Literature 40: 402-435

Frijters, P., Haisken-DeNew, J., and Shields, M.A. (2005). Changes in the pattern and determinants of life satisfaction in East and West Germany following reunification. Journal of Human Resources 24: 997-1017 
Hamermesh, D. (2004). Subjective Outcomes in Economics. Southern Economic Journal 71: $2-11$

Kahneman, D., Diener, E., and Schwarz, N. (eds) (1999). Well-Being: The Foundation of Hedonic Psychology. New York: Russell Sage Foundation.

Kahneman, D., Krueger, A.B., Schkade, D.A., Schwarz, N., and Stone, A.A., (2004). A Survey Method for Characterizing Daily Life Experience: The Day Reconstruction Method. Science 306:1776-1780

Kennedy-Moore, E., Greenberg, M., Newman, M., and Stone, A.A. (1992). The relationship between daily events and mood: The mood measure may matter. Motivation and Emotion 16:143-155

Krueger, A.B., and Schkade, D.A. (2008). The reliability of subjective well-being measures. Journal of Public Economics 92:1833-1845

Larsen, R. J., and Kasimatis, M. (1990). Individual differences in entrainment of mood to the weekly calendar. Journal of Personality and Social Psychology 58:164-171

Larsen, R.J., and Kasimatis, M. (1991). Day-to-day physical symptoms: Individual differences in the occurrence, duration, and emotional concomitants of minor daily illnesses. Journal of Personality 59: 387-423

Mihalcea, R. and Liu, H. (2006). A corpus-based approach to finding happiness. In N. Nicolov, F. Salvetti, M. Liberman, and J. H. Martin (Eds.), Computational Approaches to Analyzing Weblogs: Papers from the 2006 Spring Symposium, Menlo Park, CA.139-144. AAAI Press. Technical Report SS-06-03

Maldonado, G., and Kraus, J. F. (1991). Variation in suicide occurrence by time of day, day of the week, month, and lunar phase. Suicide and Life-Threatening Behavior 21:174-187

McFarlane, J., Martin, C.L., and Williams, T.M. (1988). Mood fluctuations: Women versus men and menstrual versus other cycles. Psychology of Women Quarterly 12: 201-223

Neale, J. M., Hooley, J. M., Jandorf, L., and Stone, A.A. (1987). Daily life events and mood. In C. R. Snyder and C. E. Ford (Eds.), Coping with negative life events: Clinical and social psychological perspectives. New York: Plenum.

Neyman, J. and Scott, E. (1948). Consistent Estimates Based on Partially Consistent Observations. Econometrica 16: 1-32

Ng, Y.K. (1997). A Case for Happiness, Cardinalism, and Interpersonal Comparability, Economic Journal, 107: 1848-1858 
Nicholson, N., Jackson, P., and Howes, G. (1978). Shiftwork and absence: An analysis of temporal trends. Journal of Occupational Psychology 51: 127-137

Rampton, B. (2007). Neo-Hymesian linguistic ethnography in the United Kingdom. Journal of Sociolinguistics 11:584-607

Rossi, A. S., and Rossi, P. E. (1977). Body time and social time: Mood patterns by menstrual cycle phase and day of the week. Social Science Research 6:273-308.

Reis, H.T., Sheldon, K.M., Gable, S. L., Roscoe, J., and Ryan R.M. (2000). Daily WellBeing The Role of Autonomy,Competence, and Relatedness. Personality and Social Psychology Bulletin 26: 419-435

Sandvik, E., Diener, E., and Seidlitz, L. (1993). Subjective well being: Convergence and stability of self-report and non self-report measures. Journal of Personality 61: 317-342

Snyder, M., Tanke, E.D., and Berscheid, E. (1977). Social perception and interpersonal behavior: On the self-fulfilling nature of social stereotypes. Journal of Personality and Social Psychology 35:656-666

Stone, A.A., Hedges, S.M., Neale, J.M., and Satin, M.S. (1985). Prospective and crosssectional mood reports offer no evidence of a "blue Monday" phenomenon. Journal of Personality and Social Psychology 49: 129-134

Stone, A.A. (1987). Event content in a daily survey is differentially associated with concurrent mood. Journal of Personality and Social Psychology 52: 56-58

Suh, E., Diener, E., and Fujita, F. (1996). Events and subjective well-being: Only recent events matter. Journal of Personality and Social Psychology 70: 1091-1102

Taylor, M.P. (2006). Tell me why I don't like Mondays: Investigating day of the week effects on job satisfaction and psychological well-being. Journal of the Royal Statistical Society Series A 169:127-142

van Praag, B.M.S., and Ferrer-i-Carbonell, A. (2004). Happiness quantified: A satisfaction calculus approach, Oxford University Press, King’s Lynn.

van Praag, B.M.S., Frijters P. and Ferrer-i-Carbonell, A. (2003). The Anatomy of Subjective Well-Being. Journal of Economic Behavior and Organization, 51: 2949

Veenhoven, R. (1991). Is Happiness Relative? Social Science Indicators 24:1-34 
Winkelmann, L., and Winkelmann, R. (1998). Why are the unemployed so unhappy? Evidence from panel data. Economica 65: 1-15

Yang, C., Spielman, A., D’Ambrosio, P., Serizawa, S., Nunes, J., and Birnbaum, J. (2001). A single dose of melatonin prevents the phase delay associated with a delayed weekend sleep pattern. Sleep 24: 272-281 
Table 1. Descriptive statistics on the different interview days (whole sample).

\begin{tabular}{lccccc}
\hline Day of interview & $\begin{array}{c}\text { Total number } \\
\text { of interviews }\end{array}$ & $\begin{array}{c}\text { Average } \\
\text { number of } \\
\text { interviews } \\
\text { per individual }\end{array}$ & $\begin{array}{c}\text { Proportion } \\
\text { never been } \\
\text { interviewed } \\
\text { on that day }\end{array}$ & $\begin{array}{c}\text { Proportion been } \\
\text { interviewed at } \\
\text { least once but } \\
\text { not always on } \\
\text { that day }\end{array}$ & $\begin{array}{c}\text { Proportion } \\
\text { always been } \\
\text { interviewed on } \\
\text { that day }\end{array}$ \\
\hline Monday & 58,401 & 1.505 & 0.317 & 0.678 & 0.005 \\
Tuesday & 58,890 & 1.514 & 0.309 & 0.686 & 0.005 \\
Wednesday & 58,489 & 1.506 & 0.314 & 0.679 & 0.007 \\
Thursday & 52,224 & 1.344 & 0.349 & 0.646 & 0.004 \\
Friday & 49,832 & 1.281 & 0.367 & 0.625 & 0.004 \\
Saturday & 48,219 & 1.241 & 0.454 & 0.541 & 0.004 \\
Sunday & 22,223 & 0.575 & 0.673 & 0.325 & 0.001 \\
\hline
\end{tabular}


Table 2. Descriptive statistics on the different interview days separated between whether the respondent was interviewed more than 7 times or 7 times or less.

\begin{tabular}{|c|c|c|c|c|c|c|}
\hline Day of interview & $\begin{array}{c}\text { Total } \\
\text { number of } \\
\text { interviews }\end{array}$ & $\begin{array}{c}\text { Total } \\
\text { number of } \\
\text { interviews }\end{array}$ & $\begin{array}{c}\text { Average } \\
\text { number of } \\
\text { interviews } \\
\text { per } \\
\text { individual }\end{array}$ & $\begin{array}{l}\text { Proportion } \\
\text { never been } \\
\text { interviewed } \\
\text { on that day }\end{array}$ & $\begin{array}{c}\text { Proportion } \\
\text { been } \\
\text { interviewed at } \\
\text { least once but } \\
\text { not always on } \\
\text { that day } \\
\end{array}$ & $\begin{array}{l}\text { Proportion } \\
\text { always } \\
\text { been } \\
\text { interviewed } \\
\text { on that day }\end{array}$ \\
\hline \multirow{2}{*}{ Monday } & $T \leq 7$ & 12,384 & 0.697 & 0.505 & 0.494 & 0.011 \\
\hline & $T>7$ & 46,017 & 2.255 & 0.143 & 0.858 & 0.000 \\
\hline \multirow{2}{*}{ Tuesday } & $T \leq 7$ & 12,748 & 0.717 & 0.493 & 0.507 & 0.011 \\
\hline & $T>7$ & 46,142 & 2.256 & 0.138 & 0.861 & 0.000 \\
\hline \multirow{2}{*}{ Wednesday } & $T \leq 7$ & 12,571 & 0.711 & 0.497 & 0.503 & 0.015 \\
\hline & $T>7$ & 45,918 & 2.246 & 0.145 & 0.855 & 0.000 \\
\hline \multirow{2}{*}{ Thursday } & $T \leq 7$ & 11,007 & 0.621 & 0.539 & 0.461 & 0.008 \\
\hline & $T>7$ & 41,217 & 2.014 & 0.174 & 0.825 & 0.000 \\
\hline \multirow{2}{*}{ Friday } & $T \leq 7$ & 10,386 & 0.591 & 0.555 & 0.445 & 0.008 \\
\hline & $T>7$ & 39,416 & 1.923 & 0.193 & 0.807 & 0.000 \\
\hline \multirow{2}{*}{ Saturday } & $T \leq 7$ & 8,929 & 0.514 & 0.631 & 0.368 & 0.008 \\
\hline & $T>7$ & 39,290 & 1.916 & 0.289 & 0.710 & 0.000 \\
\hline \multirow{2}{*}{ Sunday } & $T \leq 7$ & 4,311 & 0.245 & 0.807 & 0.192 & 0.003 \\
\hline & $T>7$ & 17,912 & 0.881 & 0.549 & 0.451 & 0.000 \\
\hline
\end{tabular}

Note: $T$ denotes number of periods that an individual is observed. 
Table 3. Descriptive statistics of interviews by days and subgroups

\begin{tabular}{cccccccc}
\hline & \multicolumn{7}{c}{ Day of the week } \\
\cline { 2 - 8 } Sub Groups & Monday & Tuesday & Wednesday & Thursday & Friday & Saturday & Sunday \\
\hline Part-time employed & & & & & & & \\
$\quad$ Never interviewed & 0.448 & 0.447 & 0.452 & 0.489 & 0.498 & 0.536 & 0.726 \\
$\begin{array}{c}\text { Interviewed at least once } \\
\text { Full-time employed }\end{array}$ & 0.555 & 0.553 & 0.548 & 0.511 & 0.502 & 0.464 & 0.273 \\
$\quad$ Never interviewed & 0.619 & 0.618 & 0.622 & 0.649 & 0.660 & 0.688 & 0.937 \\
$\begin{array}{c}\text { Interviewed at least once } \\
\text { Unemployed }\end{array}$ & 0.381 & 0.382 & 0.378 & 0.351 & 0.340 & 0.312 & 0.163 \\
$\quad$ Never interviewed & 0.482 & 0.471 & 0.473 & 0.503 & 0.527 & 0.610 & 0.791 \\
Interviewed at least once & 0.519 & 0.529 & 0.527 & 0.497 & 0.473 & 0.389 & 0.208 \\
\hline
\end{tabular}


Table 4. Regression results.

\begin{tabular}{|c|c|c|c|c|c|c|}
\hline & \multicolumn{2}{|c|}{$\begin{array}{l}\text { Pooled Ordered } \\
\text { Probit Model }\end{array}$} & \multicolumn{2}{|c|}{$\begin{array}{c}\text { Random-effects Ordered } \\
\text { Probit Model }\end{array}$} & \multicolumn{2}{|c|}{$\begin{array}{c}\text { Quasi } \\
\text { Fixed-effects Ordered } \\
\text { Probit Model } \\
\end{array}$} \\
\hline & Coefficient & Std.err & Coefficient & Std.err & Coefficient & Std.err \\
\hline Age & -0.030 & $* * * 0.007$ & -0.052 & $* * * 0.002$ & -0.119 & $* * * 0.002$ \\
\hline Age-squared/100 & 0.038 & $* * * 0.007$ & 0.060 & $* * * 0.002$ & 0.070 & $* * * 0.002$ \\
\hline Male (=1) & -0.074 & $* * * 0.038$ & -0.152 & $* * * 0.016$ & -0.141 & $* * * 0.017$ \\
\hline Single $(=1)$ & -0.128 & $* * * 0.064$ & -0.179 & $* * * 0.015$ & -0.159 & $* * * 0.015$ \\
\hline Widowed (=1) & -0.200 & $* * * 0.085$ & -0.465 & $* * * 0.019$ & -0.435 & $* * * 0.019$ \\
\hline Divorced (=1) & -0.273 & $* * * 0.074$ & -0.253 & $* * * 0.016$ & -0.229 & $* * * 0.163$ \\
\hline Household size & 0.002 & 0.002 & -0.007 & $* 0.004$ & -0.006 & 0.004 \\
\hline \#Household member aged $[0,1]$ & 0.106 & $* * * 0.009$ & 0.263 & $* * * 0.018$ & 0.263 & $* * * 0.018$ \\
\hline \#Household member aged $[2,4]$ & -0.030 & $* * * 0.006$ & -0.041 & $* * * 0.011$ & -0.039 & $* * * 0.011$ \\
\hline \#Household member aged [5,7] & -0.032 & $* * * 0.006$ & -0.032 & $* * 0.011$ & -0.030 & $* 0.011$ \\
\hline \#Household member aged $[8,10]$ & -0.012 & $* * 0.005$ & 0.009 & 0.012 & 0.010 & 0.011 \\
\hline \#Household member aged [11,12] & -0.024 & $* * * 0.006$ & 0.004 & 0.013 & 0.007 & 0.013 \\
\hline \#Household member aged [13,14] & -0.018 & $* * * 0.005$ & 0.017 & $* 0.010$ & 0.019 & *0.010 \\
\hline \#Household member aged $[15,18]$ & 0.044 & $* * * 0.005$ & 0.100 & $* * * 0.009$ & 0.010 & $* * * 0.010$ \\
\hline Full-time employed (=1) & 0.174 & $* * * 0.011$ & 0.174 & $* * * 0.012$ & 0.188 & $* * * 0.022$ \\
\hline Part-time employed (=1) & 0.019 & $* * * 0.007$ & -0.019 & 0.014 & -0.007 & 0.014 \\
\hline Log (household income) & 0.016 & $* * * 0.001$ & 0.028 & $* * * 0.004$ & 0.023 & $* * * 0.001$ \\
\hline Average weekly working hours & -0.003 & $* * * 0.001$ & -0.002 & $* * * 0.001$ & -0.002 & $* * * 0.001$ \\
\hline Employed in second job (=1) & -0.181 & $* * * 0.049$ & -0.183 & $* 0.099$ & -0.194 & $* 0.100$ \\
\hline Log (income from second job) & 0.024 & $* * * 0.006$ & 0.024 & $* 0.013$ & 0.027 & $* 0.013$ \\
\hline High school education $(=1)$ & 0.064 & $* * * 0.004$ & 0.011 & 0.011 & -0.004 & 0.011 \\
\hline University degree $(=1)$ & 0.182 & $* * * 0.006$ & 0.299 & $* * * 0.016$ & 0.257 & $* * * 0.016$ \\
\hline Health very good (=1) & 1.538 & $* * * 0.008$ & 2.289 & $* * * 0.016$ & 2.273 & $* * * 0.016$ \\
\hline Health good $(=1)$ & 1.077 & $* * * 0.006$ & 1.607 & $* * * 0.012$ & 1.602 & $* * * 0.012$ \\
\hline Health satisfactory $(=1)$ & 0.620 & $* * * 0.006$ & 0.953 & $* * * 0.011$ & 0.952 & $* * * 0.011$ \\
\hline West Germany $(=1)$ & 3.279 & $* * * 0.025$ & 8.315 & $* * * 0.064$ & 7.022 & $* * * 0.086$ \\
\hline Migrant (=1) & -0.082 & $* * * 0.006$ & -0.367 & $* * * 0.237$ & -0.111 & $* * * 0.024$ \\
\hline Mean (Age) & - & - & - & - & 7.404 & $* * * 0.171$ \\
\hline Mean (Income) & - & - & - & - & 0.037 & $* * * 0.004$ \\
\hline Mean (Weekly work hours) & - & - & - & - & -0.001 & 0.001 \\
\hline Mean (Income from second job) & - & - & - & - & -0.010 & $* * 0.003$ \\
\hline Tuesday (=1) & 0.006 & 0.012 & 0.003 & 0.012 & 0.001 & 0.011 \\
\hline Wednesday (=1) & -0.002 & 0.011 & -0.006 & 0.011 & -0.007 & 0.012 \\
\hline Thursday (=1) & 0.006 & 0.012 & 0.004 & 0.012 & 0.003 & 0.012 \\
\hline Friday $(=1)$ & -0.015 & $* * 0.012$ & -0.025 & $* * 0.012$ & -0.021 & $* 0.012$ \\
\hline Saturday (=1) & -0.037 & $* * * 0.012$ & -0.047 & $* * * 0.012$ & -0.031 & $* * 0.012$ \\
\hline Sunday (=1) & -0.061 & $* * * 0.015$ & -0.075 & $* * * 0.015$ & -0.053 & $* * * 0.016$ \\
\hline$\mu_{1}$ & 0.241 & $* * * 0.005$ & 0.703 & $* * * 0.016$ & 0.703 & $* * * 0.161$ \\
\hline$\mu_{2}$ & 0.599 & $* * * 0.004$ & 1.687 & $* * * 0.187$ & 1.689 & $* * * 0.187$ \\
\hline$\mu_{3}$ & 0.981 & $* * * 0.003$ & 2.672 & $* * * 0.193$ & 2.674 & $* * * 0.194$ \\
\hline$\mu_{4}$ & 1.295 & $* * * 0.003$ & 3.445 & $* * * 0.193$ & 3.448 & $* * * 0.194$ \\
\hline$\mu_{5}$ & 1.924 & $* * * 0.003$ & 4.939 & ***0.199 & 4.944 & $* * * 0.199$ \\
\hline$\mu_{6}$ & 2.315 & $* * * 0.002$ & 5.850 & $* * * 0.200$ & 5.856 & $* * * 0.201$ \\
\hline$\mu_{7}$ & 2.937 & $* * * 0.002$ & 7.275 & $* * * 0.201$ & 7.282 & $* * * 0.201$ \\
\hline$\mu_{8}$ & 3.892 & $* * * 0.003$ & 9.484 & $* * * 0.205$ & 9.489 & $* * * 0.206$ \\
\hline$\mu_{9}$ & 4.557 & $* * * 0.004$ & 11.125 & $* * * 0.209$ & 11.133 & $* * * 0.209$ \\
\hline Year dummies & Yes & & Yes & & Yes & \\
\hline Month dummies & Yes & & Yes & & Yes & \\
\hline State dummies & Yes & & Yes & & Yes & \\
\hline
\end{tabular}


Standard dev. of random-effects

Log likelihood

McFadden Pseudo R-squared

Number of observations

Note: $*{ }^{* *}$, and $* * *$ indicate the $10 \%, 5 \%$ and $1 \%$ levels of statistical significance, respectively.
$1.593 * * * 0.006$

$-575095.0$

344,051 
Table 5a. Quasi-fixed-effects ordered probit estimates for different sub-groups.

\begin{tabular}{|c|c|c|c|c|c|c|c|}
\hline & \multicolumn{7}{|c|}{ Sub-groups } \\
\hline & \multicolumn{2}{|c|}{ Employed } & \multirow{2}{*}{ Unemployed } & \multirow{2}{*}{ Married } & \multirow{2}{*}{ Single } & \multirow{2}{*}{ Widowed } & \multirow{2}{*}{ Divorced } \\
\hline & Full-Time & Part-Time & & & & & \\
\hline \multirow{2}{*}{ Tuesday } & 0.001 & 0.020 & 0.013 & -0.009 & 0.041 & 0.016 & -0.001 \\
\hline & $(0.017)$ & $(0.024)$ & $(0.018)$ & $(0.014)$ & $(0.024)^{*}$ & $(0.046)$ & $(0.046)$ \\
\hline \multirow{2}{*}{ Wednesday } & -0.011 & -0.011 & 0.005 & -0.007 & 0.007 & 0.036 & -0.042 \\
\hline & $(0.017)$ & $(0.025)$ & $(0.018)$ & $(0.014)$ & $(0.024)$ & $(0.046)$ & $(0.048)$ \\
\hline \multirow{2}{*}{ Thursday } & -0.002 & 0.001 & 0.015 & -0.004 & 0.041 & -0.002 & -0.044 \\
\hline & $(0.018)$ & $(0.025)$ & $(0.018)$ & $(0.014)$ & $(0.025)$ & $(0.046)$ & $(0.048)$ \\
\hline \multirow{2}{*}{ Friday } & $-0.031^{*}$ & -0.018 & -0.018 & $-0.037 * *$ & -0.011 & 0.006 & 0.003 \\
\hline & $(0.018)$ & $(0.026)$ & $(0.019)$ & $(0.015)$ & $(0.025)$ & $(0.048)$ & $(0.049)$ \\
\hline \multirow{2}{*}{ Saturday } & $-0.063 * * *$ & $-0.062 * *$ & -0.041 & $-0.057 * * *$ & -0.006 & -0.024 & -0.069 \\
\hline & $(0.017)$ & $(0.026)$ & $(0.030)$ & $(0.015)$ & $(0.025)$ & $(0.052)$ & $(0.050)$ \\
\hline \multirow{2}{*}{ Sunday } & $-0.087 * * *$ & $-0.076^{* *}$ & $-0.081 * * *$ & $-0.102 * * *$ & -0.038 & -0.008 & 0.024 \\
\hline & $(0.022)$ & $(0.032)$ & $(0.026)$ & $(0.019)$ & $(0.032)$ & $(0.068)$ & $(0.061)$ \\
\hline $\begin{array}{l}\text { Socio-economic } \\
\text { variables }\end{array}$ & Yes & Yes & Yes & Yes & Yes & Yes & Yes \\
\hline Year dummies & Yes & Yes & Yes & Yes & Yes & Yes & Yes \\
\hline Month dummies & Yes & Yes & Yes & Yes & Yes & Yes & Yes \\
\hline State dummies & Yes & Yes & Yes & Yes & Yes & Yes & Yes \\
\hline St. dev. Of RE & $\begin{array}{c}1.620 * * * \\
(0.008)\end{array}$ & $\begin{array}{c}0.816^{* * *} \\
(0.011)\end{array}$ & $\begin{array}{c}1.689 * * * \\
(0.009)\end{array}$ & $\begin{array}{c}1.710^{* * *} \\
(0.008)\end{array}$ & $\begin{array}{c}1.479 * * * \\
(0.012)\end{array}$ & $\begin{array}{c}1.662 * * * \\
(0.026)\end{array}$ & $\begin{array}{c}1.629 * * * \\
(0.024)\end{array}$ \\
\hline \multirow{2}{*}{$\begin{array}{l}\text { Pseudo R- } \\
\text { squared } \\
\text { \# observations }\end{array}$} & 0.099 & 0.078 & 0.121 & 0.114 & 0.079 & 0.088 & 0.088 \\
\hline & 129,119 & 68,568 & 141,006 & 222,892 & 79,790 & 21,834 & 21,852 \\
\hline
\end{tabular}


Table 5b. Quasi-fixed-effects ordered probit estimates for different sub-groups.

\begin{tabular}{|c|c|c|c|c|c|c|}
\hline & \multicolumn{6}{|c|}{ Sub-groups } \\
\hline & $\begin{array}{c}\text { West } \\
\text { Germany }\end{array}$ & $\begin{array}{c}\text { East } \\
\text { Germany }\end{array}$ & Natives & Immigrants & Female & Males \\
\hline \multirow{2}{*}{ Tuesday } & $0.072 * * *$ & 0.031 & 0.004 & 0.020 & 0.019 & -0.019 \\
\hline & $(0.012)$ & $(0.025)$ & $(0.012)$ & $(0.030)$ & $(0.016)$ & $(0.017)$ \\
\hline \multirow{2}{*}{ Wednesday } & $0.059 * * *$ & 0.035 & -0.009 & 0.022 & 0.012 & -0.029 \\
\hline & $(0.012)$ & $(0.025)$ & $(0.012)$ & $(0.032)$ & $(0.016)$ & $(0.017)$ \\
\hline \multirow{2}{*}{ Thursday } & $0.076^{* * *}$ & 0.028 & 0.003 & 0.024 & 0.016 & -0.012 \\
\hline & $(0.013)$ & $(0.026)$ & $(0.013)$ & $(0.032)$ & $(0.017)$ & $(0.017)$ \\
\hline \multirow{2}{*}{ Friday } & $0.054 * * *$ & $-0.048 *$ & $-0.025 *$ & 0.010 & -0.016 & -0.027 \\
\hline & $(0.013)$ & $(0.026)$ & $(0.013)$ & $(0.032)$ & $(0.017)$ & $(0.018)$ \\
\hline \multirow{2}{*}{ Saturday } & 0.011 & 0.014 & $-0.047 * * *$ & -0.003 & $-0.032 *$ & $-0.031 *$ \\
\hline & 0.013 & $(0.026)$ & $(0.013)$ & $(0.030)$ & $(0.017)$ & $(0.018)$ \\
\hline \multirow{2}{*}{ Sunday } & $-0.031 *$ & 0.026 & $-0.064 * * *$ & $-0.060 *$ & $-0.045^{* *}$ & $-0.062 * *$ \\
\hline & $(0.018)$ & $(0.029)$ & $(0.017)$ & $(0.031)$ & $(0.021)$ & $(0.023)$ \\
\hline \multicolumn{7}{|l|}{ variables } \\
\hline Year dummies & Yes & Yes & Yes & Yes & Yes & Yes \\
\hline Month dummies & Yes & Yes & Yes & Yes & Yes & Yes \\
\hline State dummies & Yes & Yes & Yes & Yes & Yes & Yes \\
\hline \multirow{2}{*}{ St. dev. of RE } & $1.696^{* * *}$ & $1.675^{* * *}$ & $1.628 * * *$ & $1.417 * * *$ & $1.589 * * *$ & $1.590 * * *$ \\
\hline & $(0.007)$ & $(0.014)$ & $(0.007)$ & $(0.016)$ & (0.009) & $(0.009)$ \\
\hline \multirow{2}{*}{$\begin{array}{l}\text { Pseudo R-squared } \\
\text { \#observations }\end{array}$} & 0.096 & 0.138 & 0.226 & 0.067 & 0.220 & 0.227 \\
\hline & 272,543 & 75,816 & 294,713 & 48,982 & 178,148 & 166,203 \\
\hline
\end{tabular}


Table 5c. Quasi-fixed-effects ordered probit estimates for different age groups.

\begin{tabular}{lcccccc}
\hline & \multicolumn{6}{c}{ Age groups } \\
\cline { 2 - 6 } & Age $\leq 25$ & $25<$ Age $\leq 35$ & $35<$ Age $\leq 45$ & $45<$ Age $\leq 55$ & $55<$ Age $\leq 65$ & Age $>65$ \\
\hline Tuesday & 0.052 & $0.057^{* *}$ & -0.043 & 0.004 & -0.022 & 0.006 \\
& $(0.031)$ & $(0.028)$ & $(0.027)$ & $(0.031)$ & $(0.030)$ & $(0.030)$ \\
Wednesday & 0.024 & 0.011 & -0.042 & 0.004 & 0.012 & -0.029 \\
& $(0.032)$ & $(0.028)$ & $(0.027)$ & $(0.031)$ & $(0.030)$ & $(0.030)$ \\
Thursday & 0.053 & -0.011 & -0.017 & 0.025 & 0.013 & -0.030 \\
& $(0.032)$ & $(0.030)$ & $(0.028)$ & $(0.032)$ & $(0.031)$ & $(0.030)$ \\
Friday & 0.023 & -0.033 & -0.032 & -0.020 & -0.029 & -0.039 \\
Saturday & $(0.032)$ & $(0.030)$ & $(0.029)$ & $(0.032)$ & $(0.031)$ & $(0.033)$ \\
Sunday & -0.014 & -0.032 & $-0.065^{* *}$ & $-0.059^{*}$ & -0.048 & -0.053 \\
Socio- & $(0.032)$ & $(0.030)$ & $(0.029)$ & $(0.033)$ & $(0.033)$ & $(0.035)$ \\
economic & -0.051 & $-0.113^{* *}$ & $-0.083^{* *}$ & $-0.069^{*}$ & -0.038 & -0.058 \\
variables & $(0.041)$ & $(0.037)$ & $(0.036)$ & $(0.041)$ & $(0.042)$ & $(0.049)$ \\
Year & Yes & Yes & Yes & Yes & Yes & Yes \\
dummies & & & & & & \\
Month & Yes & Yes & Yes & Yes & Yes & Yes \\
dummies & Yes & Yes & Yes & Yes & Yes & Yes \\
State & Yes & Yes & Yes & Yes & Yes & Yes \\
dummies & & & & & & \\
St. dev. of & $1.372^{* * *}$ & $1.626^{* * *}$ & $1.768^{* * *}$ & $1.847^{* * *}$ & $1.881^{* * *}$ & $1.713^{* * *}$ \\
RE & $(0.014)$ & $(0.015)$ & $(0.014)$ & $(0.017)$ & $(0.016)$ & $(0.017)$ \\
Pseudo R- & 0.097 & 0.165 & 0.166 & 0.154 & 0.207 & 0.142 \\
squared & & & & & & \\
\#observations & 50,116 & 62,470 & 67,970 & 53,334 & 54,849 & 48,996 \\
\hline
\end{tabular}

Note. All specifications are based on the quasi-fixed-effects ordered probit model. Subjective well-being is the dependent variable taking values from 0 to 10 . Standard errors are given in parentheses. *, **, and *** indicate the $10 \%, 5 \%$ and $1 \%$ levels of statistical significance, respectively. 
Table 6. Interviewer (within) fixed-effects estimate for different sub-groups.

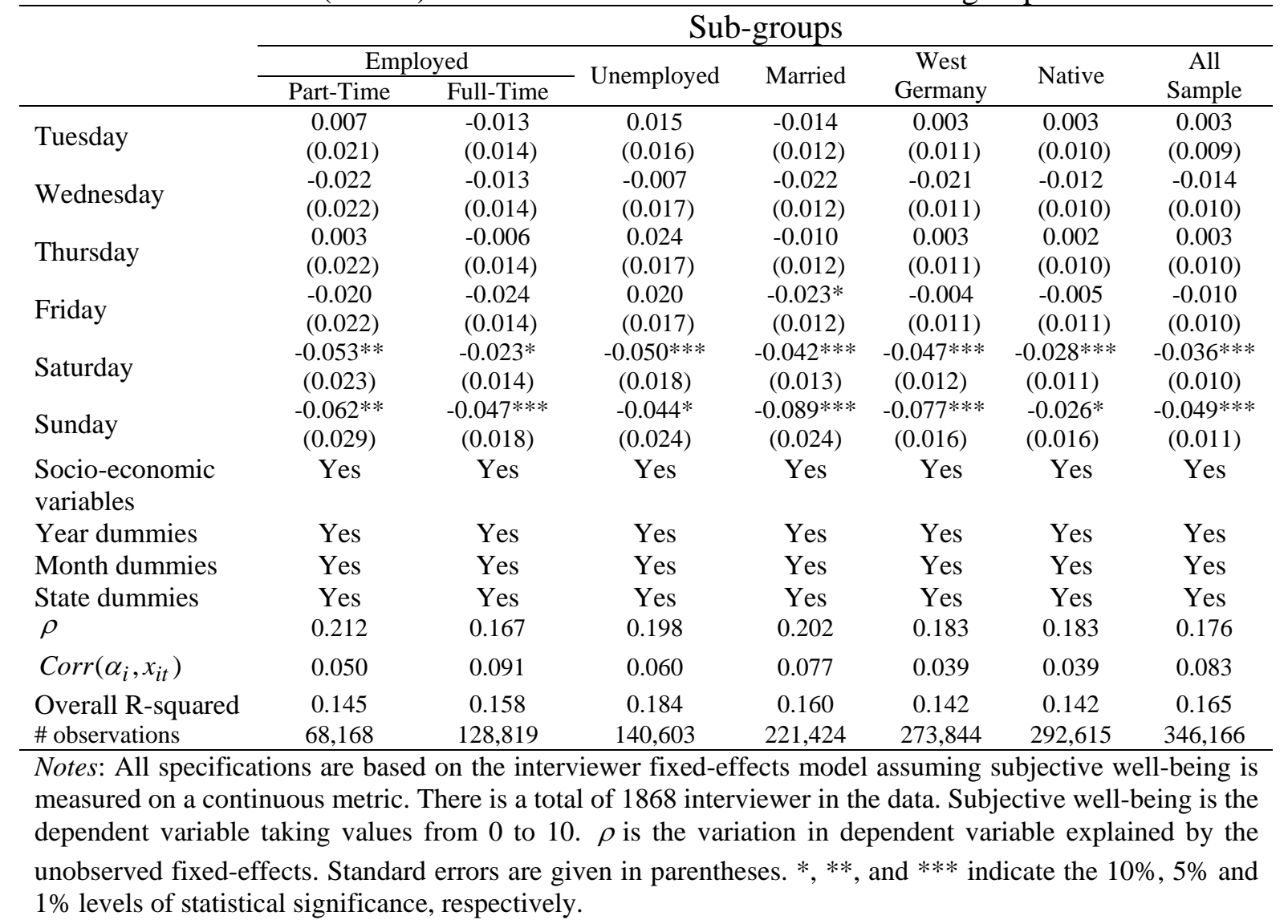


Table 7. Specifications with self-selection.

\begin{tabular}{|c|c|c|c|c|}
\hline & & \multicolumn{3}{|c|}{ Two-stage regressions } \\
\hline & & Saturday & Sunday & Saturday or Sunday \\
\hline All sample & & $\begin{array}{c}-0.060^{* * *} \\
(0.012)\end{array}$ & $\begin{array}{c}-0.093^{* * *} \\
(0.013)\end{array}$ & $\begin{array}{c}-0.062^{* * *} \\
(0.011)\end{array}$ \\
\hline & Part-time & $\begin{array}{c}-0.068 * * * \\
(0.011)\end{array}$ & $\begin{array}{c}-0.076 * * * \\
(0.012)\end{array}$ & $\begin{array}{c}-0.075^{* * * *} \\
(0.010)\end{array}$ \\
\hline Employed & Full-time & $\begin{array}{l}-0.022 \\
(0.016)\end{array}$ & $\begin{array}{c}-0.091^{* * *} \\
(0.017)\end{array}$ & $\begin{array}{c}-0.039 * * * \\
(0.015)\end{array}$ \\
\hline Unemployed & & $\begin{array}{c}-0.064 * * * \\
(0.016)\end{array}$ & $\begin{array}{c}-0.097 * * * \\
(0.018)\end{array}$ & $\begin{array}{c}-0.070 * * * \\
(0.016)\end{array}$ \\
\hline Married & & $\begin{array}{c}-0.051^{* * *} \\
(0.014)\end{array}$ & $\begin{array}{c}-0.148^{* * * *} \\
(0.014)\end{array}$ & $\begin{array}{c}-0.070^{* * * *} \\
(0.013)\end{array}$ \\
\hline $\begin{array}{l}\text { West } \\
\text { Germany }\end{array}$ & & $\begin{array}{c}-0.066^{* * *} \\
(0.013)\end{array}$ & $\begin{array}{c}-0.180 * * * \\
(0.013)\end{array}$ & $\begin{array}{c}-0.071^{* * *} \\
(0.012)\end{array}$ \\
\hline Native & & $\begin{array}{c}-0.112^{* * *} \\
(0.013)\end{array}$ & $\begin{array}{c}-0.166^{* * *} \\
(0.013)\end{array}$ & $\begin{array}{c}-0.128 * * * \\
(0.012)\end{array}$ \\
\hline
\end{tabular}

Notes: All specifications are based on the two-stage method and each stage is estimated with the quasi-fixedeffects approach. The first stage includes three exogenous instruments: whether the respondent experienced a change of interviewer, mode of the interview (four dummies: oral, written with interviewer, written without interviewer, computer-assisted telephone interview), and mean number of interviews conducted on a particular day (6 dummies). These instruments are excluded from the second-stage estimation and predicted values of first stage are included in the second-stage subjective well-being equation. Standard errors are given in parentheses. *, **, and *** indicate the $10 \%, 5 \%$ and $1 \%$ levels of statistical significance, respectively. 
Figure 1. Average subjective well-being levels by days of the week for the whole sample.

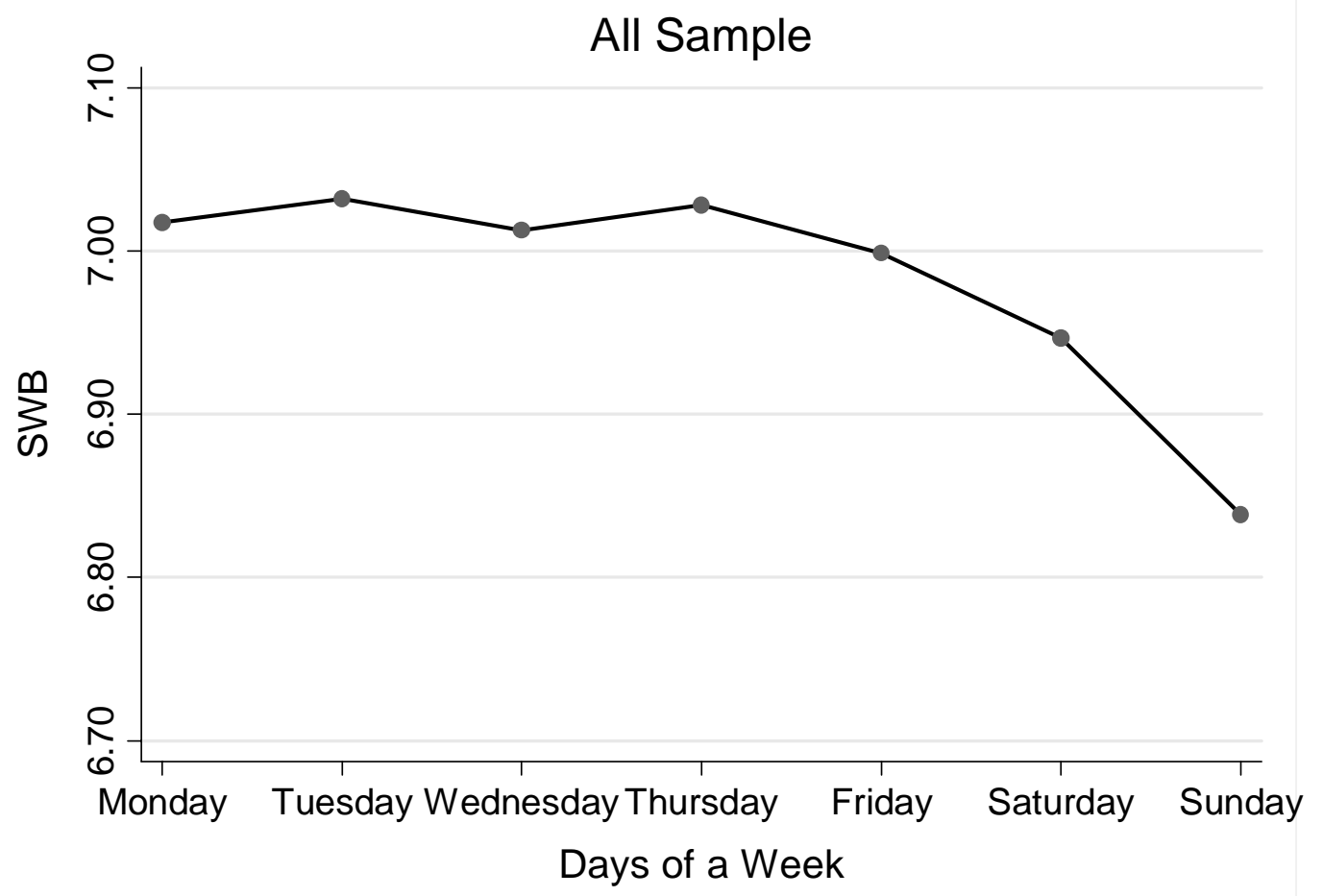


Figure 2. Average subjective well-being levels by days of the week for full-time employed, part-time employed and unemployed.
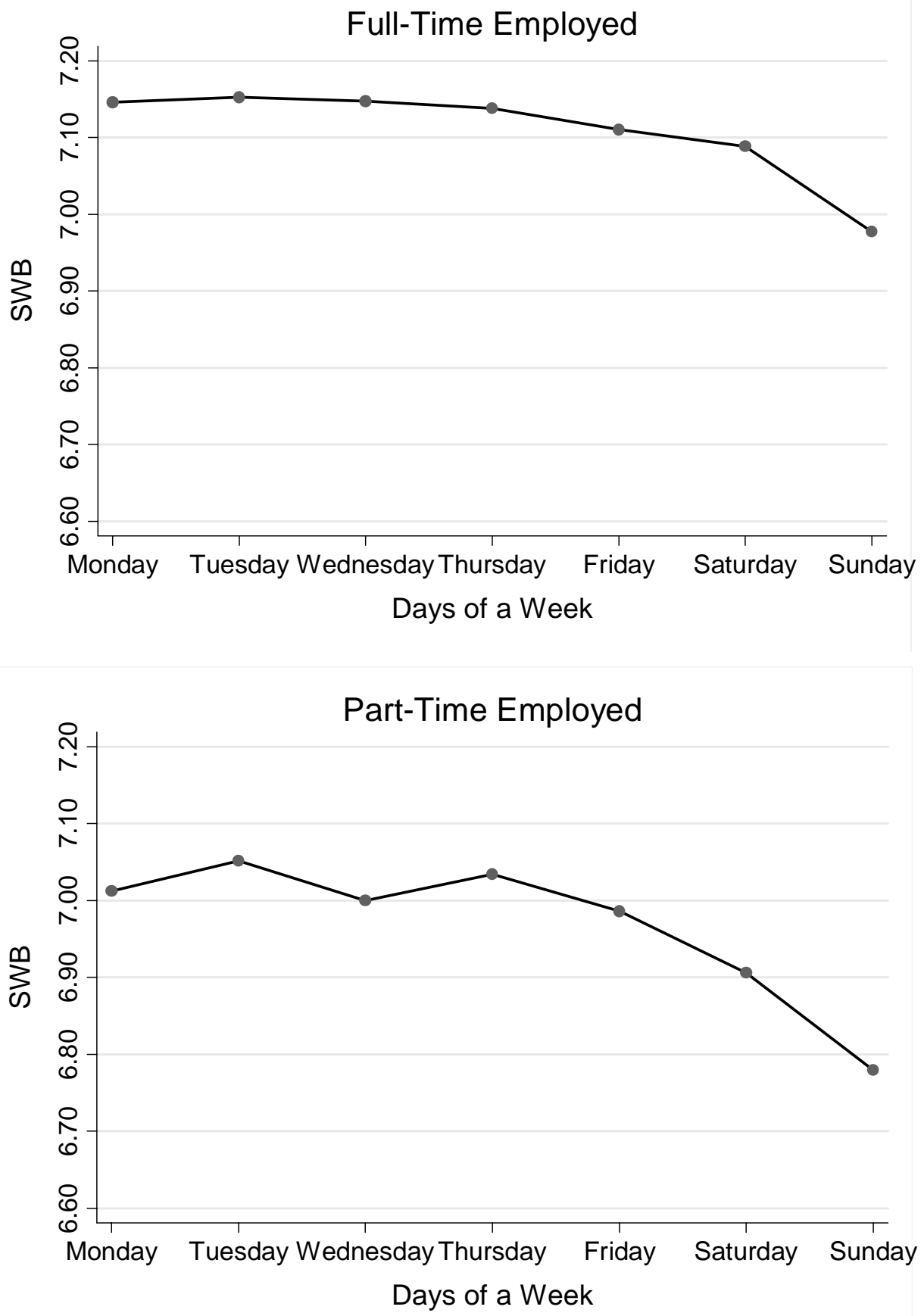


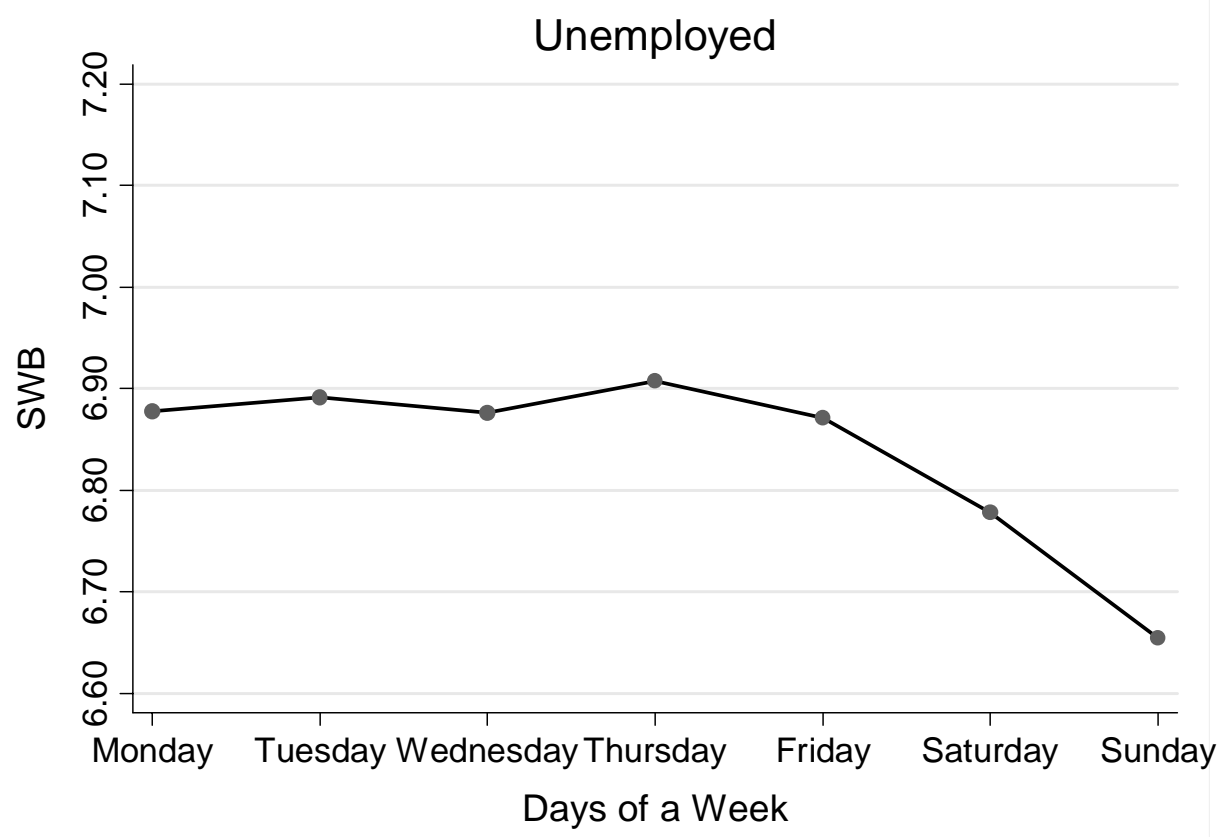


Figure 3a. Average subjective well-being levels by days of the week for married, single, divorced and widowed.
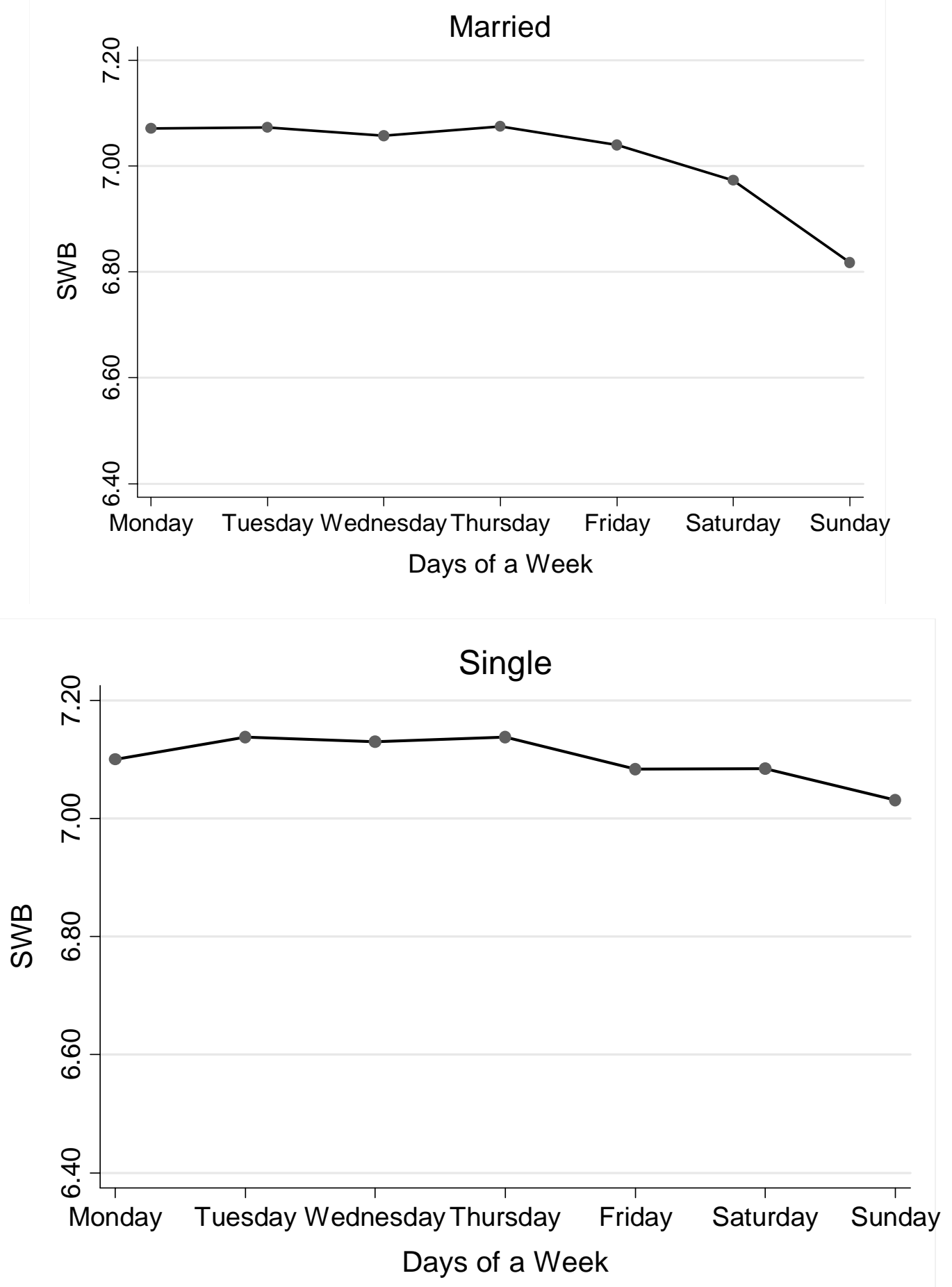

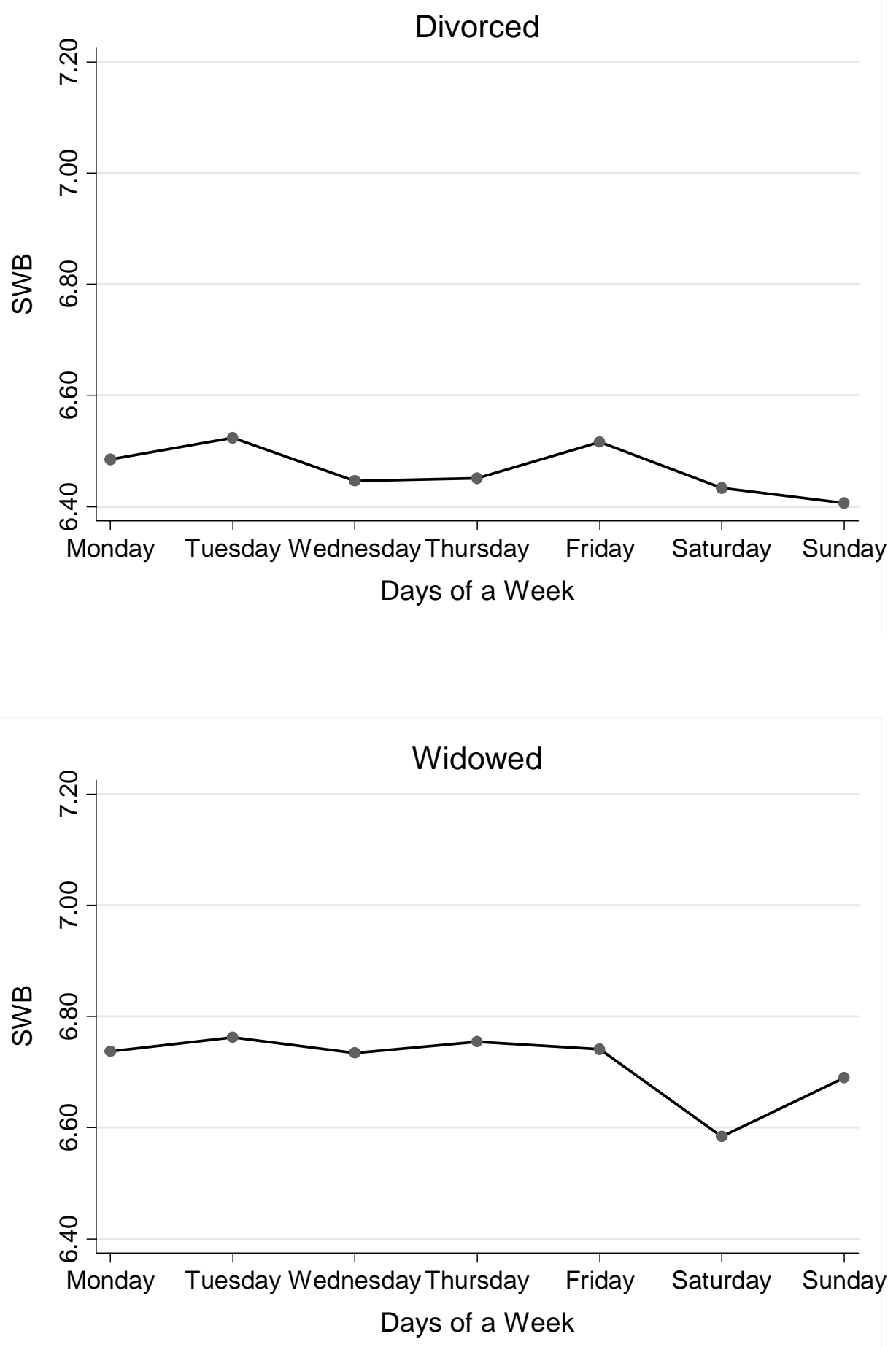
Figure 4. Average subjective well-being levels by days of the week for West and East Germans.
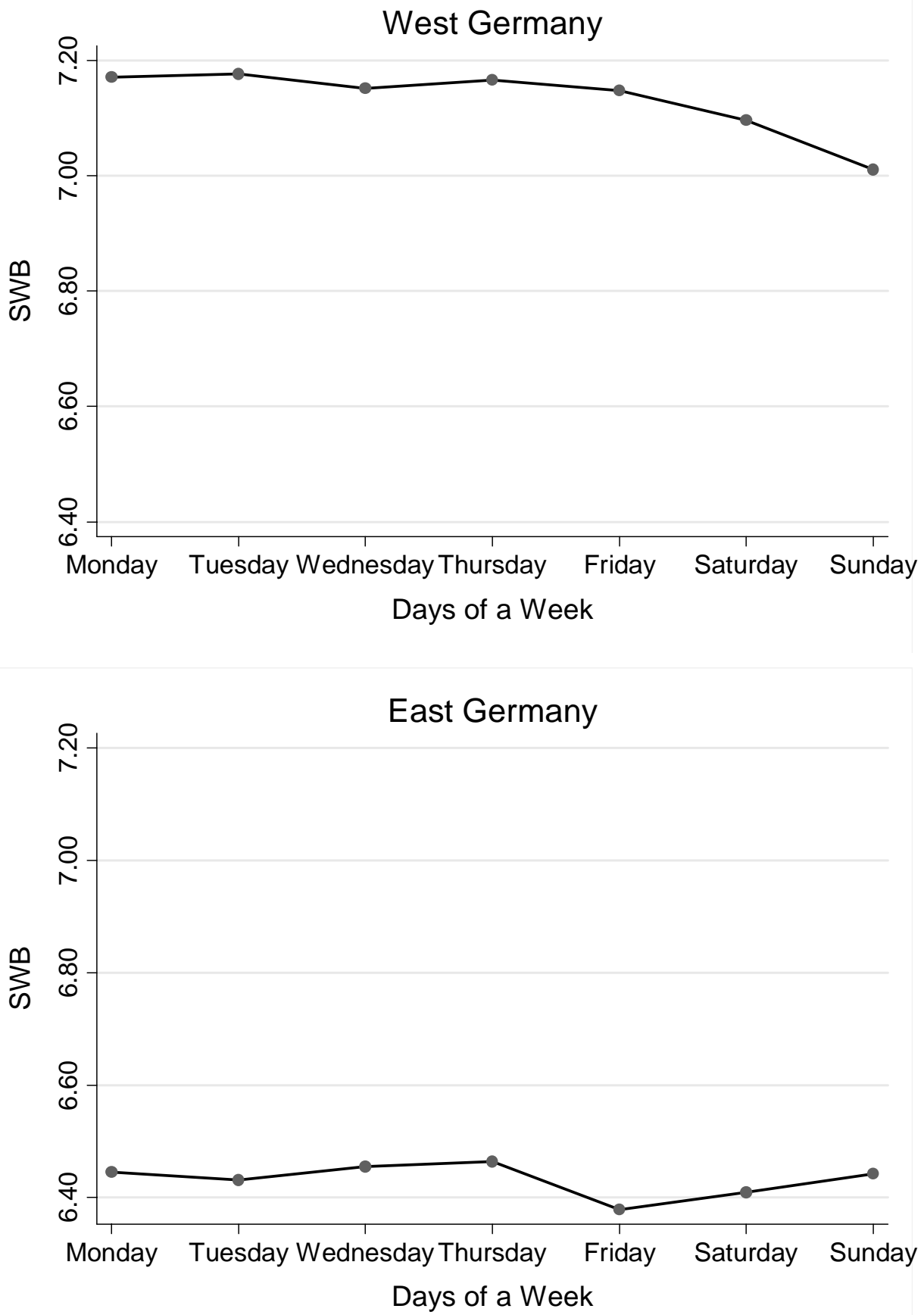
Figure 5. Average subjective well-being levels by days of the week for native Germans and immigrants .
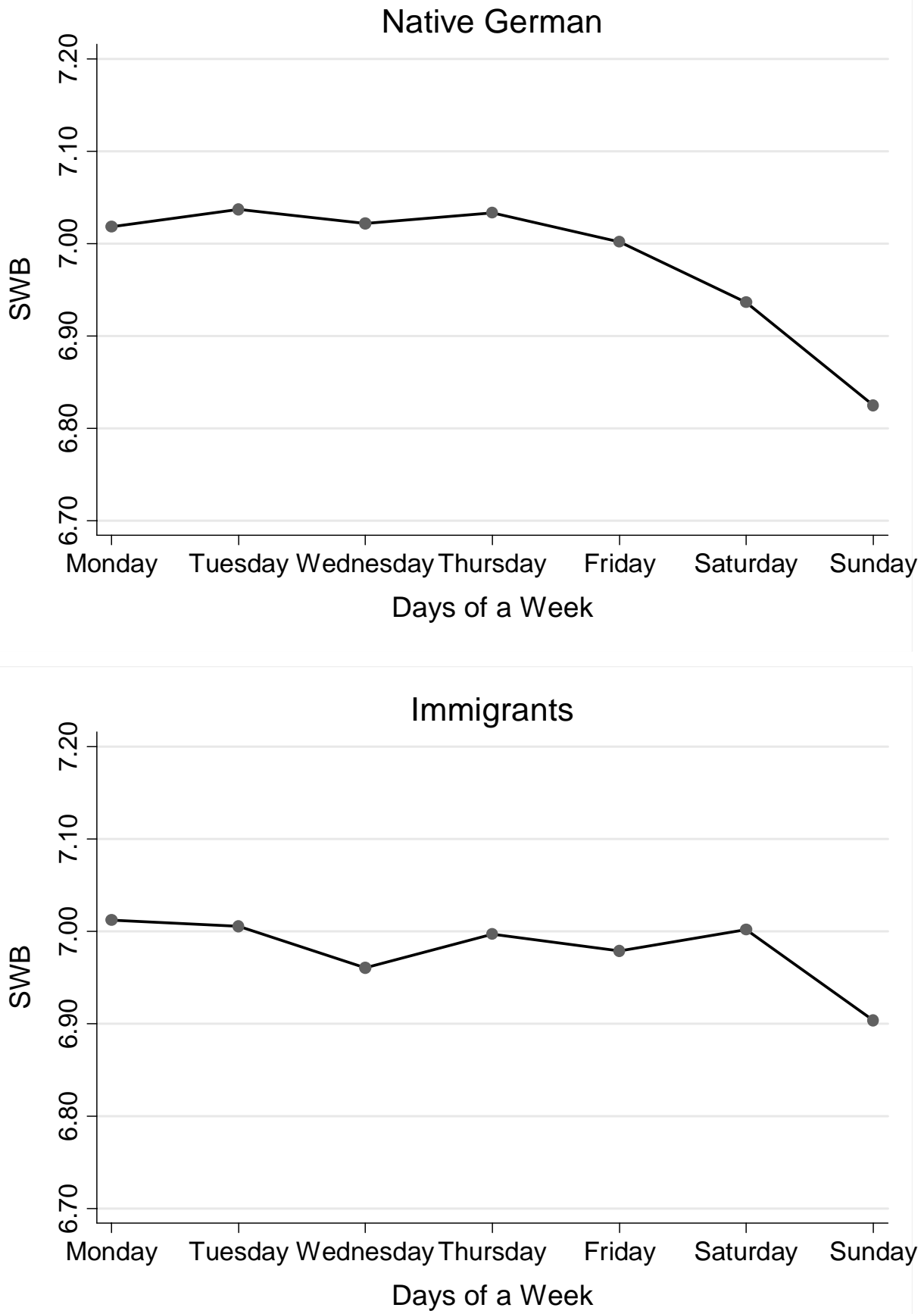
Figure 6. Average subjective well-being levels by days of the week for female and males.
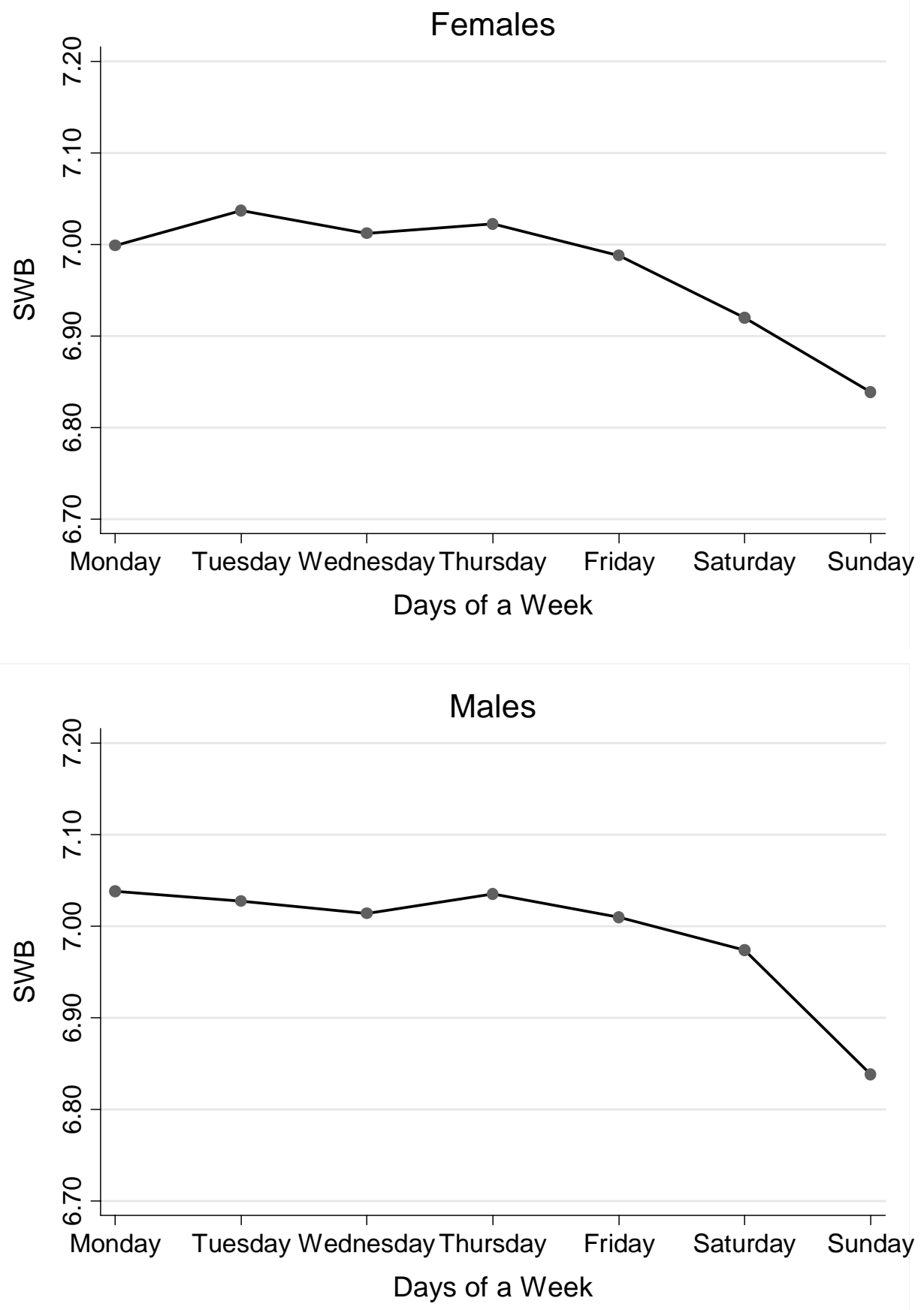
Figure 7. Average subjective well-being levels by days of the week for age categories.
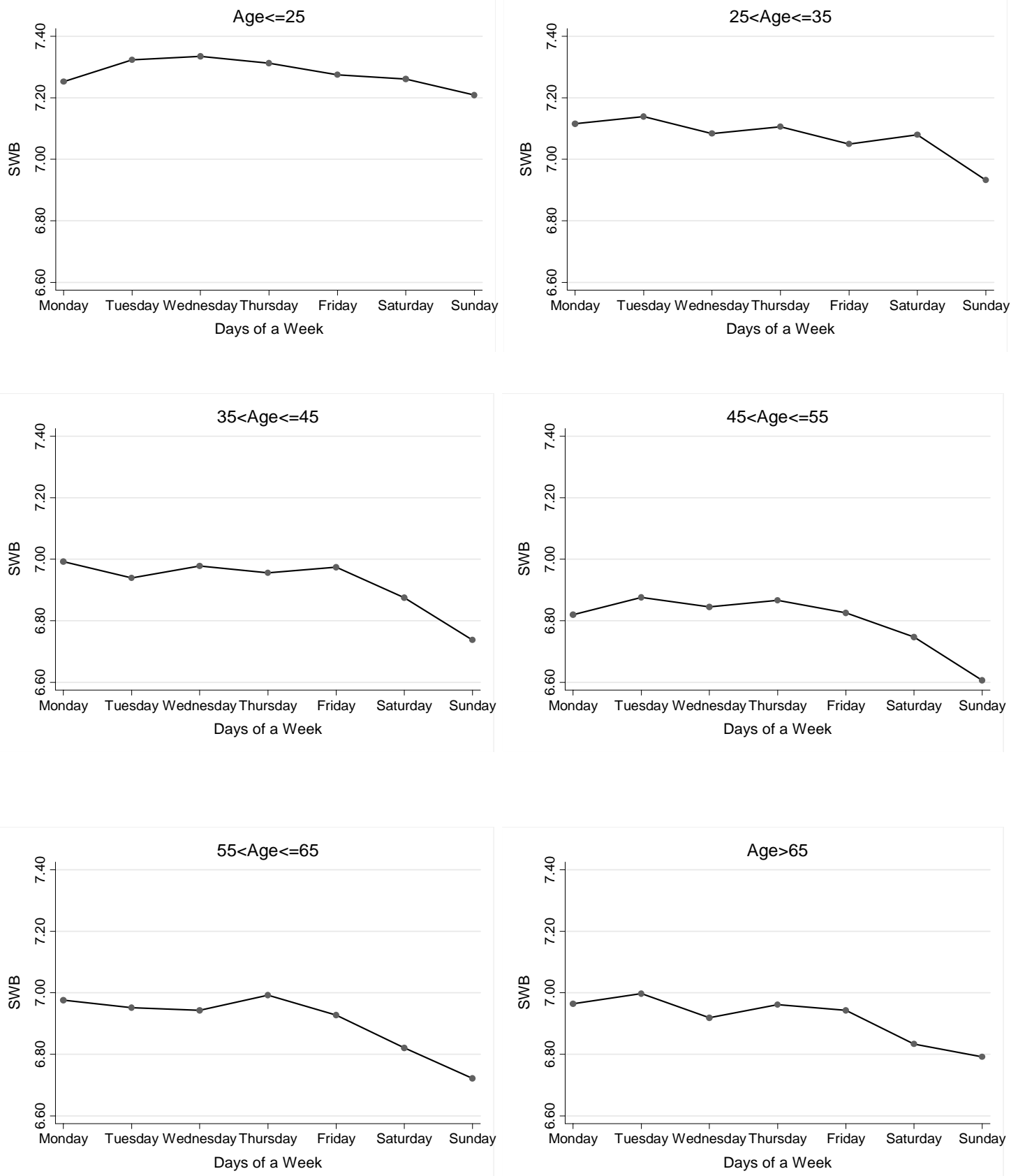